\title{
An Overview of NASA's SubsoniC Research Aircraft Testbed (SCRAT)
}

\author{
Ethan Baumann, ${ }^{1}$ Joe Hernandez, ${ }^{2}$ and John Ruhf ${ }^{3}$ \\ NASA Dryden Flight Research Center, Edwards, California, 93523
}

\begin{abstract}
National Aeronautics and Space Administration Dryden Flight Research Center acquired a Gulfstream III (GIII) aircraft to serve as a testbed for aeronautics flight research experiments. The aircraft is referred to as SCRAT, which stands for SubsoniC Research Aircraft Testbed. The aircraft's mission is to perform aeronautics research; more specifically raising the Technology Readiness Level (TRL) of advanced technologies through flight demonstrations and gathering high-quality research data suitable for verifying the technologies, and validating design and analysis tools. The SCRAT has the ability to conduct a range of flight research experiments throughout a transport class aircraft's flight envelope. Experiments ranging from flight-testing of a new aircraft system or sensor to those requiring structural and aerodynamic modifications to the aircraft can be accomplished. The aircraft has been modified to include an instrumentation system and sensors necessary to conduct flight research experiments along with a telemetry capability. An instrumentation power distribution system was installed to accommodate the instrumentation system and future experiments. An engineering simulation of the SCRAT has been developed to aid in integrating research experiments. A series of baseline aircraft characterization flights has been flown that gathered flight data to aid in developing and integrating future research experiments. This paper describes the SCRAT's research systems and capabilities.
\end{abstract}

\section{Nomenclature}

AC $=$ alternating current

ACTE $=$ Adaptive Compliant Trailing Edge

AFRL $\quad=$ Air Force Research Laboratory

AFSRB $=$ Airworthiness and Flight Safety Review Board

ARR $\quad=$ ACTE risk reduction

CDR $=$ Critical Design Review

CFD $\quad=$ Computational Fluid Dynamics

COTS $=$ commercial off-the-shelf

$\mathrm{CPT}=$ control position transducer

DC $\quad=$ direct current

DFRC $=$ Dryden Flight Research Center

DRE $\quad=$ Discrete Roughness Element

DRELFGE $=$ DRE Laminar Flow Glove Experiment

EGI $=$ embedded GPS INS

ERA $=$ Environmentally Responsible Aviation

FAA $\quad=$ Federal Aviation Administration

FOSS $\quad=$ fiber optic sensing system

FRR $\quad=$ Flight Readiness Review

FTE $\quad=$ Flight Test Engineer

$\mathrm{G} \quad=$ gravity

GIII $\quad=$ Gulfstream III

\footnotetext{
${ }^{1}$ SCRAT Chief Engineer, Controls and Dynamics Branch, P.O. Box 273/MS 4840D, AIAA non-member

${ }^{2}$ SCRAT Instrumentation Lead, Flight Instrumentation Branch, P.O. Box 273/MS 2228, AIAA non-member

${ }^{3}$ SCRAT Operations Lead, Flight Operations Branch, P.O. Box 273/MS 4830B, AIAA non-member
} 


\begin{tabular}{|c|c|c|}
\hline GPS & $=$ & global positioning system \\
\hline IADS & $=$ & Interactive Display System \\
\hline INS & $=$ & inertial navigation system \\
\hline INU & $=$ & inertial navigation unit \\
\hline IR & $=$ & infrared \\
\hline IRIG-B & $=$ & inter range instrumentation group mod B \\
\hline KCAS & $=$ & knots calibrated airspeed \\
\hline $\mathrm{M}$ & $=$ & Mach number \\
\hline MCR & $=$ & Mission Concept Review \\
\hline Mmo & $=$ & maximum operating Mach \\
\hline MOA & $=$ & Memorandum of Agreement \\
\hline MOU & $=$ & Memorandum of Understanding \\
\hline NASA & $=$ & National Aeronautics and Space Administration \\
\hline NRC & $=$ & National Research Council \\
\hline NTP & $=$ & network time protocol \\
\hline ORD & $=$ & Objectives and Requirements Document \\
\hline PC & $=$ & personal computer \\
\hline PCM & $=$ & pulse code modulation \\
\hline PDR & $=$ & Preliminary Design Review \\
\hline PDS & $=$ & power distribution system \\
\hline PID & $=$ & Parameter Identification \\
\hline $\mathrm{RF}$ & $=$ & radio frequency \\
\hline SCRAT & $=$ & SubsoniC Research Aircraft Testbed \\
\hline SRR & $=$ & Systems Requirement Review \\
\hline TAMU & $=$ & Texas A\&M University \\
\hline TM & $=$ & telemetry \\
\hline TRL & $=$ & Technology Readiness Level \\
\hline Vmca & $=$ & minimum controllable airspeed \\
\hline Vmo & $=$ & maximum operating velocity \\
\hline Vstall & $=$ & stall speed \\
\hline WATR & $=$ & Western Aeronautical Test Range \\
\hline
\end{tabular}

\section{Introduction}

$\mathrm{T}$ The National Research Council's (NRC)'s report on “Recapturing NASA's Aeronautics Flight Research Capabilities"1 made several recommendations regarding the development of flight research experiments and testbed aircraft. The report recommends, "NASA should ensure that each of its projects has a defined path to inflight testing in an appropriate environment." Another recommendation is to "... develop flight research vehicles to demonstrate innovative aerospace technology in flight." In line with these recommendations, the National Aeronautics and Space Administration (NASA) Dryden Flight Research Center (DFRC) (Edwards, California) acquired a Gulfstream III (GIII) aircraft (Gulfstream Aerospace Corporation, Savannah, Georgia), tail number 804, to serve as a testbed for aeronautics flight research experiments. The aircraft is commonly referred to as SCRAT, which stands for SubsoniC Research Aircraft Testbed (Fig. 1). The aircraft is used to perform aeronautics research, and more specifically to raise the Technology Readiness Level (TRL) of advanced technologies, through flight demonstration, and gathering high-quality research data suitable for verifying the technologies and validating design and analysis tools. Historically, experimental aerodynamic and fluid mechanics investigations were primarily conducted in ground-based wind-tunnel facilities. However, these wind-tunnel facilities often imposed certain limitations such as scaling effects related to using sub-scale wind-tunnel models and an inability to match Reynolds number, noise levels, and boundary conditions. ${ }^{2}$ In some instances, conducting an investigation in flight using the flying wind-tunnel concept, where an aircraft is used as a carrier vehicle for an experiment, some or all the windtunnel limitations can be avoided. 


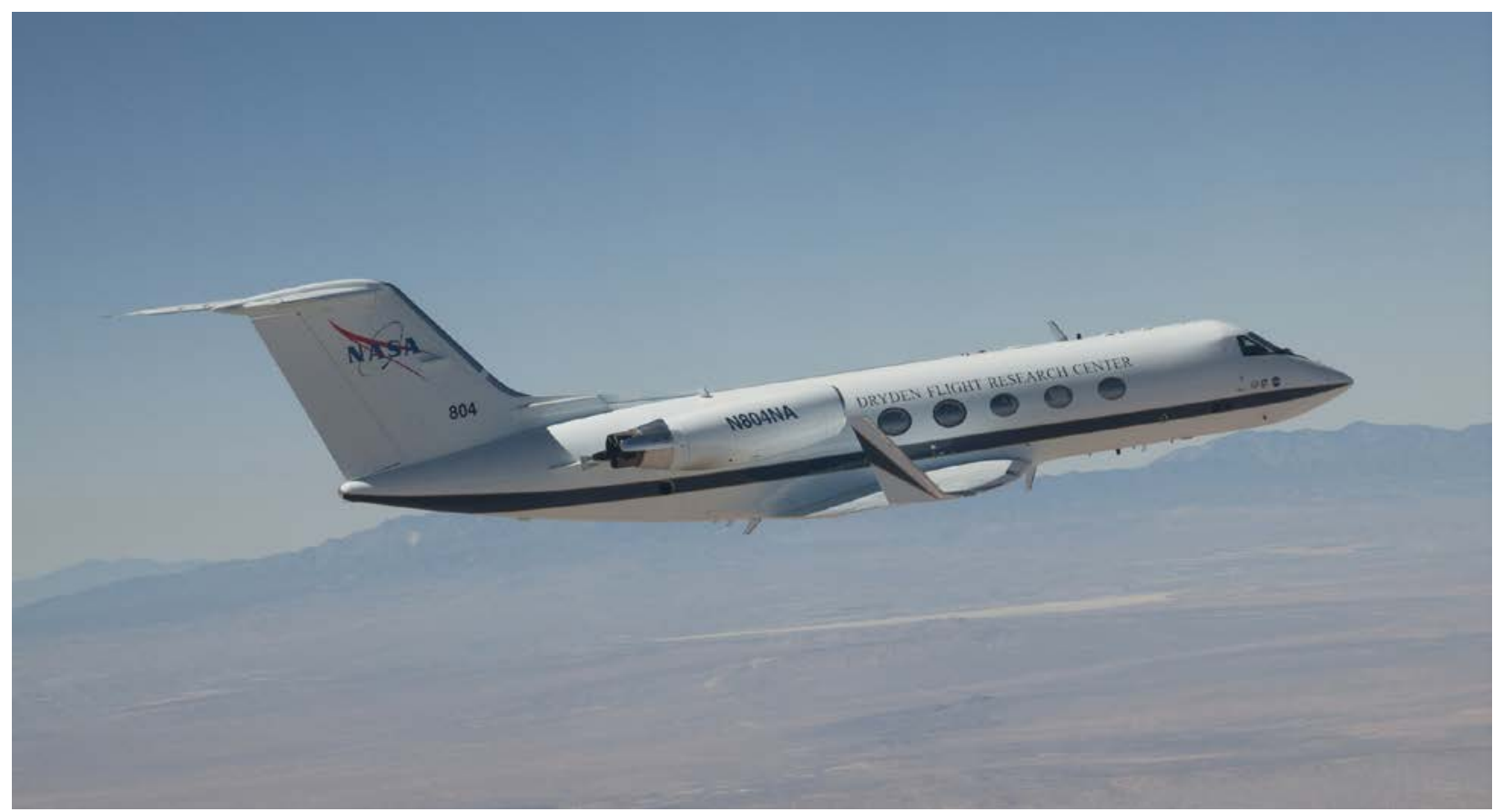

Figure 1. SCRAT in flight.

The SCRAT was identified in the NRC's report as an example of the type of flight research and testbeds that NASA should be developing. This paper provides an overview of SCRAT's research capabilities along with additional ground based tools that support the aircraft. In addition, two SCRAT flight research projects are discussed to provide examples of the aircraft's capabilities as a research platform.

\section{SCRAT Overview}

The SCRAT has been developed as a flight research platform for the purpose of raising the TRL of advanced, environmentally responsible technologies suitable for transport class aircraft. To serve this purpose, the SCRAT has been outfitted with a research quality instrumentation system. The SCRAT power system has been modified to support a power distribution system designed to accommodate the instrumentation and research systems. In addition, the cabin interior includes workstations for researchers and instrumentation engineers to monitor research experiments and aircraft systems. A telemetry capability has been added to the SCRAT, which allows for control room monitoring of critical parameters during envelope expansion flights, and allows for additional ground based researchers to monitor the status of their experiments.

A series of flight tests, known as the baseline aircraft characterization flights, has been conducted to gather flight data suitable for characterizing the aircraft's aerodynamics and for gathering data required to support follow-on experiments. Data from these flights have been used in documenting the aircraft's baseline stability and control characteristics prior to planned modifications. The baseline flights also characterized the airdata system to ensure that research quality aircraft state and performance data can be obtained.

An engineering simulation has been developed which models the SCRAT's flight characteristics. The simulation contains aircraft models tailored to simulate the SCRAT systems and performance. The aircraft models have been updated based on flight data obtained during the baseline flights, therefore the simulation provides an accurate representation of SCRAT's in-flight handling qualities, flight dynamics, and flight performance. In addition, a fixed based simulation capability has been created which allows the pilots to examine the aircraft's flight characteristics with research experiments added. Engineers and pilots use this simulation to conduct airworthiness analysis to clear the aircraft for flight with the research experiments.

The SCRAT research systems, aircraft modifications, baseline flight data, and engineering simulation provide a powerful capability for flight-testing of advanced aeronautics research experiments. In addition, the experience gained from modifying and operating the SCRAT is contained in an experienced, multi-disciplinary team at NASA DFRC that is ready to support flight research experiments. 


\section{Vehicle Description}

The SCRAT is a GIII, which is a twin-turbofan, swept-wing, and business jet built by Gulfstream Aerospace Corporation. The SCRAT is powered by two Rolls Royce Spey RB turbofan engines (163-25) 511-8 (Rolls Royce Group PLC, London, England), which are capable of providing a maximum continuous power of 10,940 lb at sea level. Thrust reversers are fitted to each engine to reduce landing distance. Figure 2 contains a 3-view of the SCRAT. Table 1 details the SCRAT dimensions along with the allowable weights, airspeeds, altitudes, and G-limits. The service ceiling of the SCRAT is $45,000 \mathrm{ft}$ and the maximum velocity is 340 Knots Calibrated Air Speed (KCAS) and a maximum Mach number of 0.85 . The full SCRAT flight envelope, which does vary by the gross weight of the aircraft, is provided in Fig. 3. The SCRAT has an empty weight of approximately 38,000 lb and a maximum takeoff weight of $69,700 \mathrm{lb}$. Maneuvering limitations placed on the SCRAT consist of $-1 \mathrm{~g}$ to $2.5 \mathrm{~g}$ with the fowler flaps retracted and decrease to $0 \mathrm{~g}$ to $2 \mathrm{~g}$ with the fowler flaps extended.

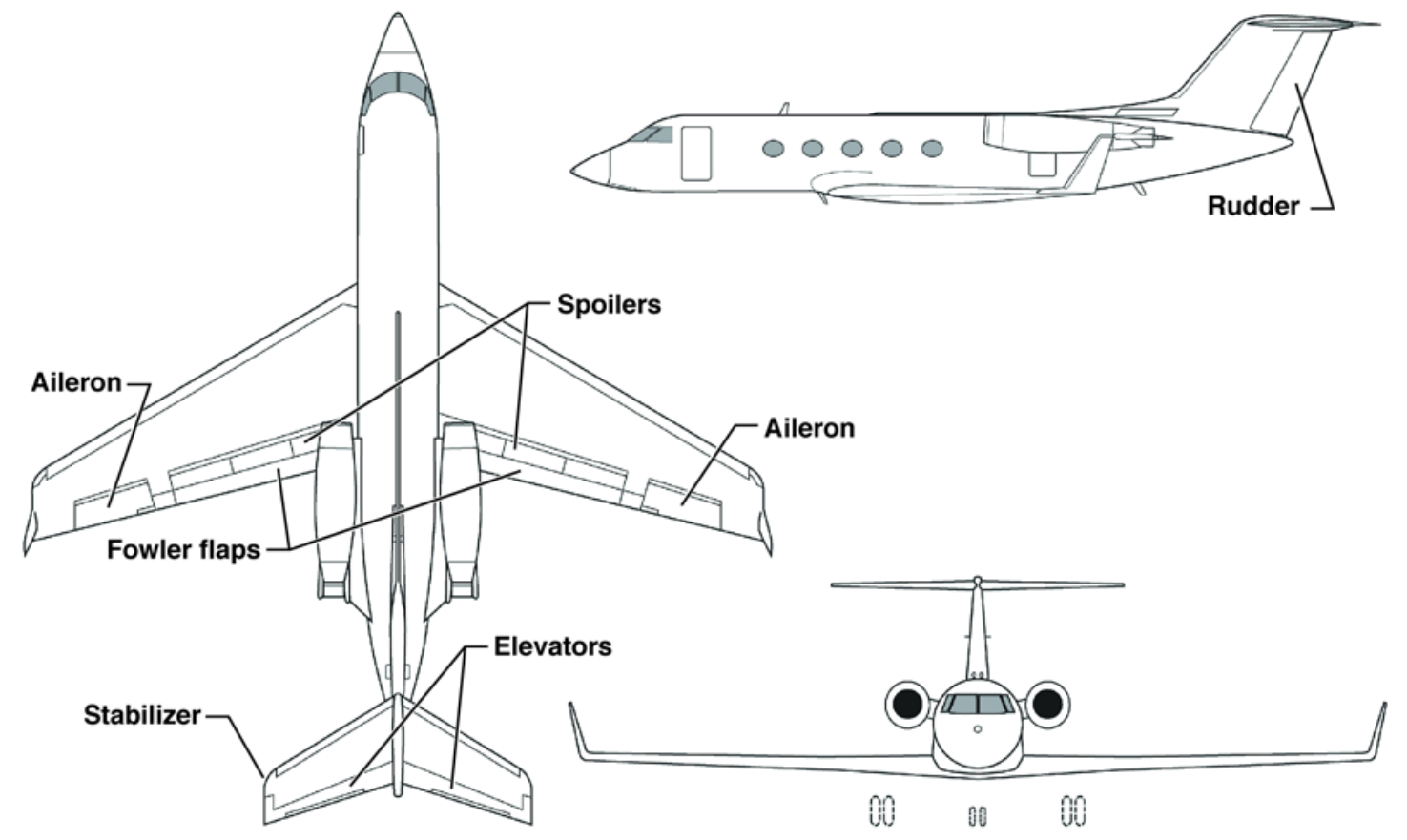

Figure 2. 3-view of the SCRAT. 


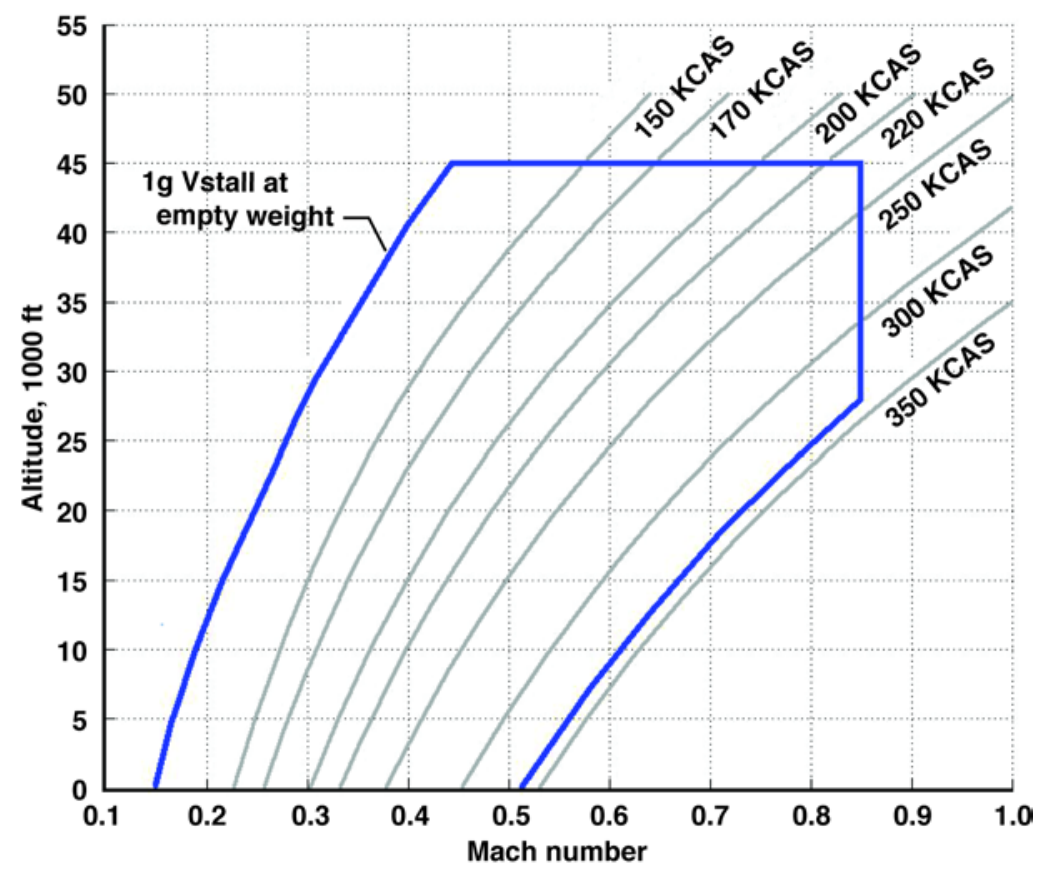

Figure 3 . SCRAT flight envelope.

Table 1. SCRAT dimensions and operating limits.

\begin{tabular}{cll}
\hline \hline \multirow{5}{*}{ Dimensions } & Length & $83 \mathrm{ft} 2 \mathrm{in}$ \\
& Wingspan & $77 \mathrm{ft} 10 \mathrm{in}$ \\
& Height & $24 \mathrm{ft} 4.5 \mathrm{in}$ \\
& Wing area & $934.6 \mathrm{ft}^{2}$ \\
& Mean aerodynamic chord & $12 \mathrm{ft} 3 \mathrm{in}$ \\
& Aspect ratio & $6: 1$ \\
& Wing sweep & 36 degrees \\
\hline \multirow{3}{*}{ Weights } & Empty weight & $38,000 \mathrm{lb}$ \\
& Max takeoff weight & $69,700 \mathrm{lb}$ \\
& Max landing weight & $58,500 \mathrm{lb}$ \\
\hline \multirow{5}{*}{ Airspeeds } & Max operating altitude & $45,000 \mathrm{ft}$ \\
& Vmo (max operating velocity) & $392 \mathrm{mph} / 340$ knots \\
& Mmo (max operating mach) & 0.85 \\
& Vmca (minimum controllable & $115 \mathrm{mph} / 100 \mathrm{knots}$ \\
& airspeed) & \\
& M (max range cruise) & $0.75-0.76$ \\
\hline \multirow{2}{*}{ Performance } & Max range & $3400 \mathrm{~nm}$ \\
& Endurance & $\mathrm{Up}$ to $7 \mathrm{hours,}$ \\
& & typically $<=5$ hours \\
\hline \multirow{2}{*}{ G-limits } & G limits - fowler flaps retracted & $-1 \mathrm{~g}$ to $2.5 \mathrm{~g}$ \\
& G limits - flower flaps extended & $0 \mathrm{~g}$ to $2.0 \mathrm{~g}$ \\
\hline \hline
\end{tabular}

The SCRAT has been modified to support research experiments within the nominal SCRAT transport-classaircraft flight envelope, and operations throughout the entire SCRAT nominal flight envelope were demonstrated during the baseline flights. Future large-scale flight experiments integrated onto SCRAT might result in flight 
envelope restrictions depending on the nature of the experiment and the structural, aerodynamic, and control limitations of the SCRAT.

Either the pilot or copilot can fly the SCRAT through the use of their control yoke and rudder pedals. These pilot inceptors are directly connected to each control surface through a series of cables and pulleys. In addition, tandem type hydraulic actuators are used to operate each control surface in order to reduce control forces. Longitudinal control is provided by the elevator control surface, with longitudinal trim control provided by the elevator trim surface. The SCRAT stabilizer is coupled with the aircraft fowler flaps to longitudinally re-trim the aircraft as the flaps deploy and retract. The ailerons and spoilers are mechanically linked to provide lateral control. Lateral trim is achieved through the use of the aileron trim. The rudder provides directional control, with the rudder trim providing the directional trim capability. Fowler flaps are used for takeoff and landing. In addition, the spoilers deploy after touchdown to decrease landing distance. The pilots are aided by an autopilot system and yaw damper.

The maximum cruise range for the SCRAT is $3,400 \mathrm{~nm}$. The SCRAT is capable of flying up to 7 hours assuming cruise conditions. To date, SCRAT flights have ranged from approximately 2 hours to approximately 5.5 hours.

SCRAT unique limitations are rules prohibiting flight through visible moisture and avoidance of all precipitation while on the ground. These limitations are required to protect the unique research systems and sensors located external to the aircraft cabin.

\section{SCRAT Concepts of Operation}

The SCRAT has been developed with the capability to support a large range of flight experiments relevant to multiple disciplines. The experiments can range from sensor development, to testing of new aircraft and research sensors and systems, to aircraft aerodynamic modifications, to advanced cockpit displays, and to airspace management. SCRAT lacks a research flight control capability, but does have the potential to support controls experiments related to autopilot development or testing of new control actuators. The range of experiments that can be accommodated is largely limited by the imagination of the researcher. The possible experiments generally fall into two categories: large and small-scale flight research experiments. Large-scale flight research experiments are defined as those experiments, which require significant structural, aerodynamic, system, instrumentation, or control changes to the aircraft. Examples of large-scale flight research experiments are modifications to the wing shape and replacing existing control surfaces with novel structures. Small-scale flight research experiments are defined as those experiments, which do not require significant structural, aerodynamic, system, instrumentation, or control changes to the aircraft. Examples of small-scale experiments are flight-testing of a new external sensor, new GPS receiver, or another system requiring little more than power and data connections.

\section{A. Experiment Development, Integration, and Flight Process}

The lifecycle for experiments flown on SCRAT go through four distinct phases: experiment proposal phase, design phase, buildup and integration phase, and a flight phase. Figure 4 shows an overview of the experiment development, integration, and flight process along with a summary of the activities during each phase and the typical design reviews. Early on in the development of a flight experiment, the DFRC project team, DFRC chief engineer, and the experimenter will jointly tailor the process to meet the specific needs of each flight experiment flown on SCRAT. The process shown in Fig. 4 is representative of that for large-scale experiments, and certain elements may be shortened or combined for small-scale experiments. 


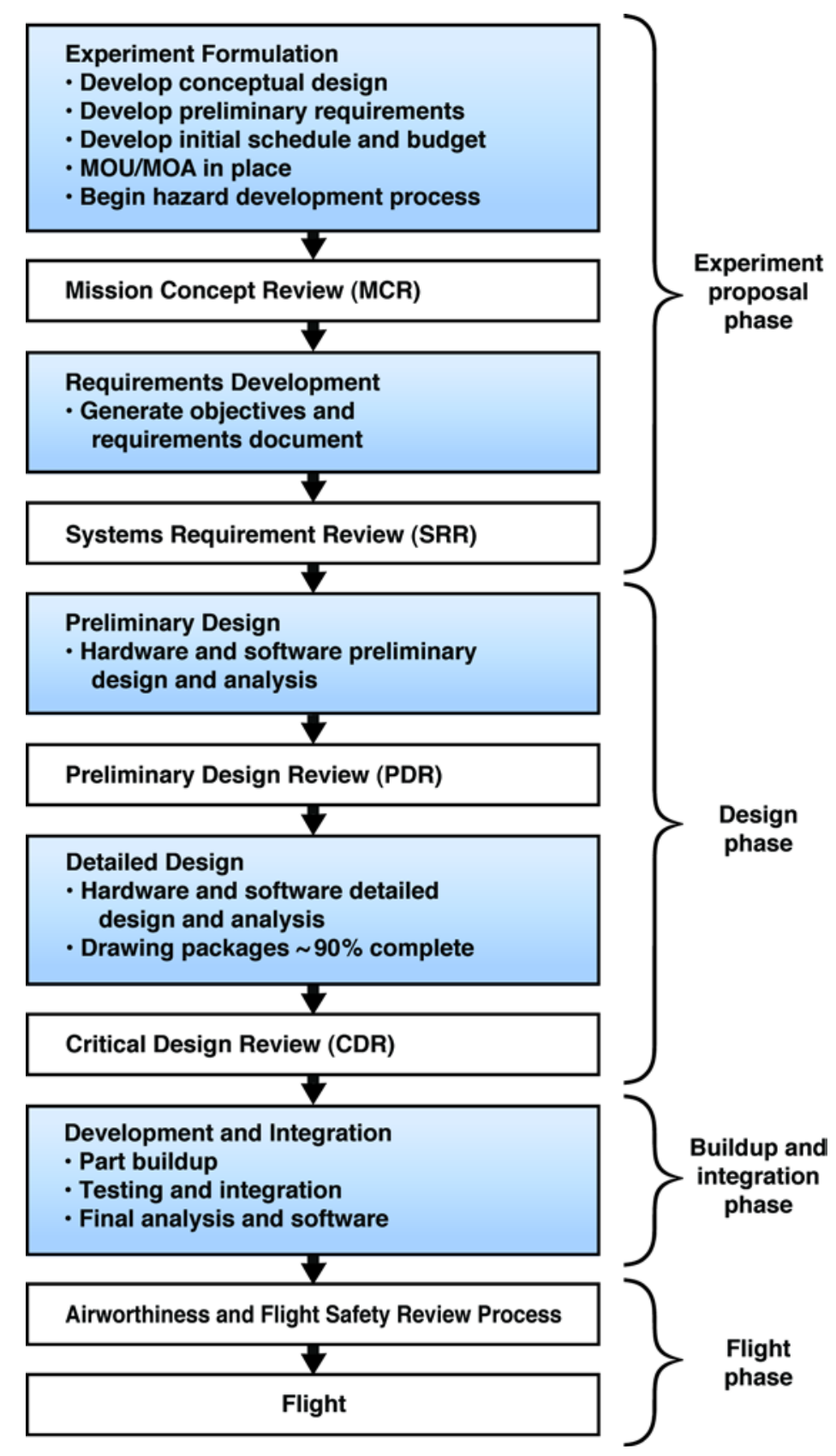

Figure 4. Overview of the experiment development, integration, and flight process.

\section{Experiment Proposal Phase}

The Experiment Proposal phase lays the foundation for potential collaboration through research, test, and evaluation between NASA DFRC and potential experimenters. The intent during this phase of the mission planning is to define the scope, objectives, requirements, schedule, cost, and hazards associated with a mission or experiment. A conceptual design is generated during this time to aid in requirements development. The generation of a Memorandum of Agreement (MOA) or Memorandum of Understanding (MOU) between NASA DFRC and the customer occurs during this phase. A Mission Concept Review (MCR) may take place during the experiment proposal phase in order to provide an independent review of the conceptual design and the plans for the project.

All SCRAT experiments require an Objectives and Requirements Document (ORD) generated by the experimenter with the assistance of the SCRAT project team. This document is the key to defining specific objectives and requirements of the flight experiment. Information contained in the ORD includes the experiment 
objectives, scope, approach, requirements, hardware/software requirements, qualifications, and ground test requirements.

The experiment proposal phase culminates in a Systems Requirement Review (SRR). At the SRR, the experiment scope, objectives, and requirements are examined in detail to ensure they are well defined, well understood, and achievable. The conceptual design, preliminary hazards, budget, and schedule are also discussed at the SRR.

\section{Experiment Design Phase}

Once the SRR has been successfully completed, and the ORD has been agreed to by all parties, the experiment enters the design phase. During this phase, the hardware and software aspects of the experiment are designed, airworthiness analysis begins, and a detailed approach is developed for integrating the experiment onto SCRAT. Airworthiness analysis is conducted to assess any experiment specific unique changes, which affect the SCRAT's flight characteristics. Airworthiness analysis can include work by the SCRAT aerodynamics, flight controls, flight systems, and flight structures disciplines. Also during this time, the requirements and schedule are continuously tracked, and project and technical risks, and hazards are addressed. The design of experiment systems and equipment installations for use on SCRAT will follow standard aircraft industry design practice and Gulfstream design criteria. Current Federal Aviation Administration (FAA) standards are to be met to the maximum extent practical, consistent with the mission objectives.

A preliminary flight-test plan is developed during this time frame. The flight-test plan will detail the flight conditions, flight maneuvers, and unique flight requirements for each experiment. The flight-test plan is useful in determining the number of flights and flight hours required for each experiment.

Typically, a Preliminary Design Review (PDR) is held at a mid-point in the design phase to provide an independent assessment of the state of the design and to solicit input from the stakeholders. The design phase culminates in a Critical Design Review (CDR) where the nearly finalized experiment design and related analysis is presented. Ideally, any experiment drawing packages are approximately $90 \%$ complete and very little, if any, flight hardware has been built or procured prior to CDR. Independent review teams are present at both the PDR and CDR in order to provide an outside perspective and expert opinion on the experiment design and progress.

\section{Buildup and Integration Phase}

Once the CDR has been completed, the procurement and build-up of the flight hardware begins, and the flight software is developed. The experiment hardware and software is tested extensively during this timeframe with some testing occurring prior to aircraft integration, and more testing occurring once integrated with the aircraft systems.

DFRC is responsible for the integration of all experiments onto the SCRAT and will work closely with experimenters to ensure the proper integration. During this phase, requirements are tracked and verified either through test, analysis, or inspection to ensure that all experiment development requirements have been met. The airworthiness analysis unique to each experiment concludes during this phase. The flight-test plan is finalized during this phase.

The buildup and integration phase is complete once the project is ready to proceed to the flight phase and begin the DFRC airworthiness and flight safety review process.

\section{Flight Phase}

The NASA DFRC flight approval process usually includes the completion of a Flight Readiness Review (FRR), an Airworthiness and Flight Safety Review Board (AFSRB), and technical briefings. The DFRC Chief Engineer may grant deviations from the basic flight approval process. For example, smaller or less complex experiments with minimal risk are often granted FRR and AFSRB waivers after review and approval by the DFRC Chief Engineer. Larger flight experiments with more inherent complexity and risk will most likely require more reviews within the flight approval process. An experiment can be flown on SCRAT only after receiving approval from the DFRC Chief Engineer. The airworthiness review process often continues throughout the experiment flights with additional briefings occurring as needed.

Once approval has been given by the DFRC Chief Engineer to proceed, the project may begin experiment flights. Prior to any flight, the SCRAT, instrumentation system, and the experiment are configured for flight in what are known as pre-flight procedures. The pre-flight procedures typically occur one or two days prior to a flight. A crew brief occurs the day prior to a flight. At the crew brief, all personnel involved in the flight gather to discuss the flight plan. The SCRAT flights typically occur in the military range around Edwards Air Force Base, but may leave that range if required. Following a flight, a crew de-brief is held to discuss the flight events and develop plans for the 
next flight. The SCRAT, instrumentation system, and experiment are de-configured from flight status in a post-flight procedure that usually occurs the day after a flight. Flight data is available to the experimenter approximately 24 hours after the post-flight procedures are completed.

\section{B. Large Scale Flight Research Experiments}

Large-scale flight research experiments will typically require a few years to develop from conceptualization to integration and flight on SCRAT, and will follow a lengthier airworthiness review process. The DFRC SCRAT project team will work with the developers of large-scale flight research experiments from the beginning in order to ensure the experiment can be integrated and flown on the aircraft. These large-scale experiments will typically require a significant multi-disciplinary engineering effort in terms of model development, analysis, and ground testing along with a series of envelope expansion flights to expand the flight envelope. Envelope expansion flights are required for any experiment in which the SCRAT's outer mold line has been changed or for which significant structural modifications have been made. During these envelope expansion flights, the aircraft will be minimally crewed and data will be telemetered to the ground for control room monitoring. Once the aircraft has been cleared for flight in certain portions of the flight envelope, control room support becomes optional and is dependent upon research and airworthiness requirements. At this point, the control room staffing would depend on the need to support the research goals or provide additional monitoring of the safety of flight parameters. In the cases where a control room is not required, cost and time savings can be achieved by recording all data onboard with researchers present in the cabin to monitor the progress of their research experiments.

\section{Small Scale Flight Research Experiments}

The development and integration times of small-scale flight research experiments will vary depending on the complexity of the experiment and integration activities, but it could be as short as a few months. An abbreviated airworthiness review process might be applicable in some cases depending again on the complexity of the flight research experiment. The DFRC SCRAT project team will work with the developers of small-scale flight research experiments from the beginning in order to ensure the experiment can be integrated and flown on the aircraft. These small-scale experiments would likely not require envelope expansion flights, thus incurring significant cost and schedule savings compared to the large-scale experiments. Small-scale flight research experiments would be monitored in flight by the researcher or a designee sitting at a workstation on the aircraft. If desired, the control room could support these small-scale research flights, but is not generally required.

\section{Aircraft Capabilities \& Research System Description}

At the heart of the SCRAT's research capabilities is the instrumentation system. The instrumentation system interfaces with the aircraft data bus and systems along with a number of research and airworthiness sensors. This section describes the instrumentation system capabilities and the available sensors.

\section{A. Instrumentation System Description}

The instrumentation system that has been integrated onto the SCRAT collects, processes, displays, telemeters, and records data obtained from multiple sources.

The SCRAT contains an ARINC-429 (A429) avionics data bus that much of the aircraft systems interface with. The instrumentation system collects data from the aircraft A429 bus, as well as aircraft systems not on the A429 bus such as the engines and sensors located throughout the aircraft. The instrumentation system is currently configured to record approximately 1,200 parameters at data rates ranging from $1 \mathrm{~Hz}$ to $20,000 \mathrm{~Hz}$. The instrumentation system has been designed to interface with future research systems and sensors.

\section{B. Research Instrumentation Network}

The instrumentation system provides an on-board local area network available to users and systems via Ethernet. All data acquired by the instrumentation system is available through this network. Research systems and researchers will have access to the network. The instrumentation system network is not connected to the Internet and has access restrictions in place to protect the network. IRIG-B (inter range instrumentation group mod B) and NTP (network time protocol) time, synchronized by a single GPS source, is distributed throughout the aircraft. These time sources allow for accurate, correlated time sources for all on-board data. These time services are available through data panel connections located throughout the cabin. 


\section{Sensor Description}

A number of sensors have been added to the SCRAT to acquire aircraft airworthiness and research data for a variety of flight projects. The list of sensors includes: wing pressure measurements, structural accelerometers, control surface positions, aircraft state information, airdata parameters, pilot inceptor inputs and forces, a hot film array, a fiber optic sensing system (FOSS), engine parameters, and wing strain measurements. Uses for the data obtained from these sensors include estimating the SCRAT's rigid body aerodynamics, monitoring wing structural loads, assessing aircraft handling qualities and flight dynamics, measuring aircraft and engine performance, and characterizing the wing flow field.

\section{Wing Pressure Distribution}

Upper and lower wing pressure distributions are available at three span-wise locations on the left wing (Fig. 5). At these locations, pressure ports have been installed in the wing leading edge and vinyl tubing, approximately 1 in wide and 0.1 in tall, and have been adhered to the top and bottom sides of the wing for the purpose of obtaining wing pressure distribution data. This data has been used to validate Computational Fluid Dynamics (CFD) models, and will be useful in supporting future research experiments.

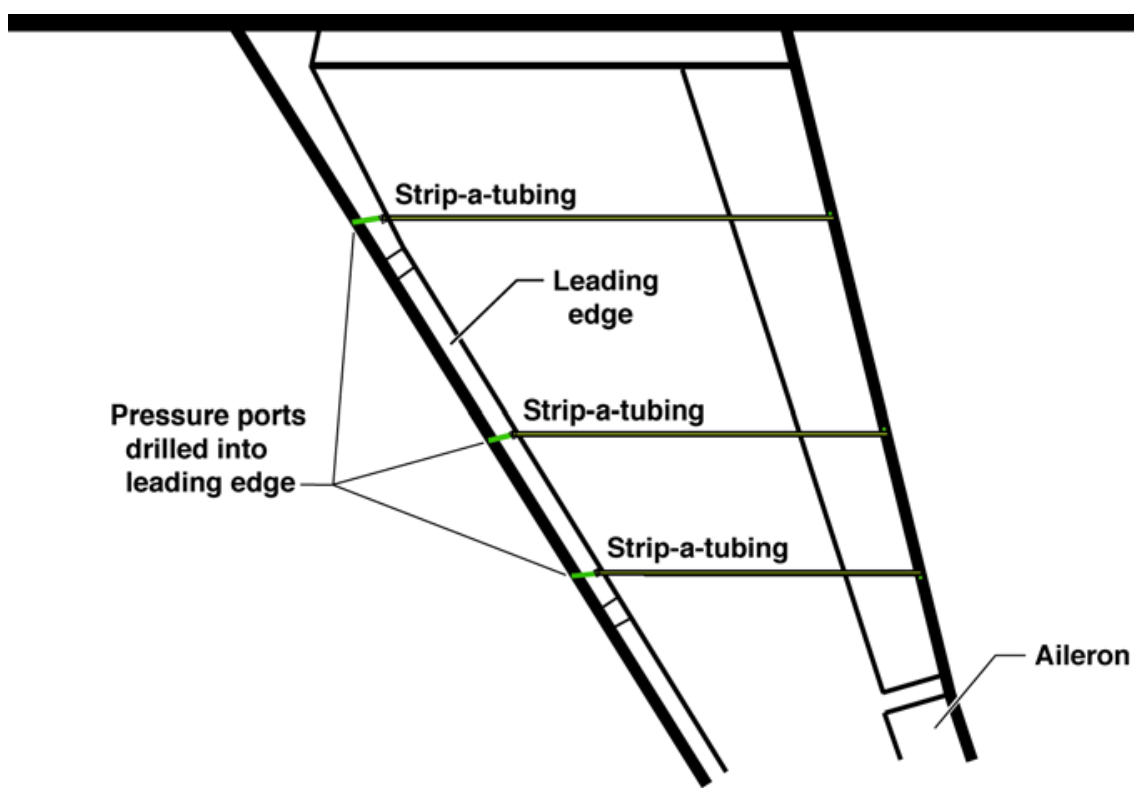

Figure 5. Location of wing pressure measurements.

\section{Structural Accelerometers}

Ten structural accelerometers have been placed on the aircraft to monitor aircraft structural modes. These accelerometers have been placed near the wing tips, the nose, and on the tail. The placement of the accelerometers allows for the measuring of the significant structural dynamics modes. Flight data from these accelerometers has been used to validate the structural dynamics model for the aircraft. Large-scale flight experiments will likely affect the aircraft's structural dynamics, so these structural accelerometers provide an existing means of assessing those impacts in flight.

\section{Control Surface Positions}

The majority of the SCRAT control surface positions have been instrumented with a control position transducer (CPT). The CPTs are mounted to a control horn or bell crank as close as possible to the individual control surface to provide the most accurate knowledge possible of the surface's position. Following is a list of the control surfaces instrumented: elevator, elevator trim, stabilizer, spoilers, ailerons, aileron trim, and rudder. The fowler flaps were not instrumented since they are set to discrete increments and are mechanically linked to the stabilizer, which is instrumented. Knowledge of control surface position is required for conducting Parameter Identification (PID) estimation of the aircraft rigid body aerodynamics. 


\section{Airdata}

The SCRAT is instrumented to acquire airdata information used to obtain knowledge of the aircraft flight condition. A combination of research quality sensors, aircraft instrumentation, and flight-based calibration curves are used to provide high-fidelity airdata measurements to support flight research. Table 2 lists the available airdata parameters.

Table 2. Available airdata parameters.

\begin{tabular}{ll}
\hline \hline Airdata parameter & Units \\
\hline Indicated static pressure & $\mathrm{psf}$ \\
Total pressure & $\mathrm{psf}$ \\
Total temperature & $\mathrm{deg} \mathrm{F}$ \\
Impact pressure & $\mathrm{psf}$ \\
Corrected impact pressure & $\mathrm{psf}$ \\
Indicated Mach number & \\
Freestream Mach number & \\
Freestream static pressure & $\mathrm{psf}$ \\
Freestream state temperature & $\mathrm{deg} \mathrm{F}$ \\
Pressure altitude & $\mathrm{ft}$ \\
Dynamic pressure & $\mathrm{psf}$ \\
True velocity/ airspeed & $\mathrm{knots}$ \\
Indicated airspeed & $\mathrm{knots}$ \\
Equivalent airspeed & $\mathrm{knots}$ \\
Calibrated airspeed & $\mathrm{knots}$ \\
Freestream viscosity & $\mathrm{lb}-\mathrm{sec} / \mathrm{ft}^{2}$ \\
Freestream density & $\mathrm{lbm} / \mathrm{ft}^{3}$ \\
Reynolds number & $1 / \mathrm{ft}^{2}$ \\
\hline \hline
\end{tabular}

In addition to the above listed airdata measurements, four flow angularity vanes have been fastened to the SCRAT's radome to provide angle-of-attack and angle-of-sideslip measurements. Figure 6 shows the location of three of the flow angularity vanes on the SCRAT radome, with the 4th vane out of view. Flight data was used to develop calibrations for both parameters. The resulting calibrations for angle of attack are accurate to $\pm 0.26^{\circ}$ and angle of sideslip is accurate to $\pm 0.55^{\circ}$. 


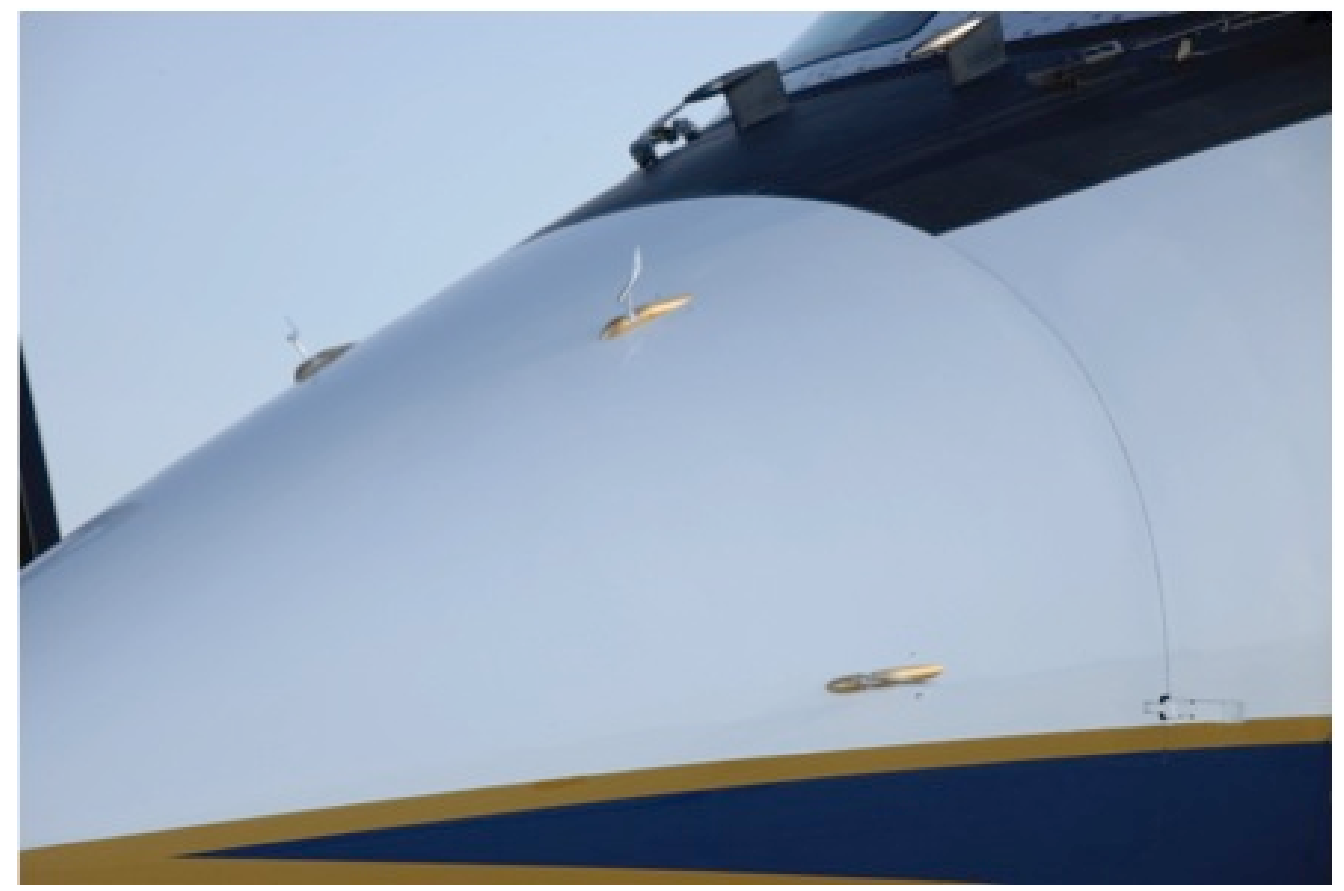

Figure 6. Flow angularity vanes $\left(4^{\text {th }}\right.$ vane not visible $)$.

\section{Aircraft State Information}

Aircraft state information is obtained through a combination of sensors. The SCRAT contains two aircraft inertial navigation units (INU)s that are used in conjunction with two research INUs installed on the aircraft to obtain three-axis aircraft attitude, rate, and acceleration data. The SCRAT production aircraft systems also provide aircraft velocity and position information. An embedded GPS INS (EGI) system is currently being integrated onto the aircraft in order to provide highly accurate aircraft angular rate, acceleration, velocity, and position information.

\section{Control Inceptor Input Force and Position}

The pilot's yoke and rudder pedals are instrumented to measure pilot inceptor forces and position. The yoke longitudinal and lateral positions and input forces are measured along with the rudder position and input force. These data have been used to improve the fidelity of the ground-based piloted engineering simulation and is monitored in flight as an indication of pilot workload and aircraft state.

\section{Hot Film Sensor Array}

A 32-element Senflex hot-film sensor array ${ }^{3}$ has been placed on the leading edge of the left wing. The hot-film array allows for non-intrusive measurements of the airflow. These measurements allow for identification of laminar to turbulent flow transition, stagnation points, shocks, boundary layer instabilities, and flow separation. A data acquisition system has been developed and integrated onto SCRAT to interface with the hot-film array. The hot film system is capable of acquiring data at $20,000 \mathrm{~Hz}$. The hot film array is currently being used to measure wing stagnation point and could be relocated as needed, or additional hot-film arrays could be placed on the aircraft. Figure 7 shows the hot film array located on the left wing leading edge. 


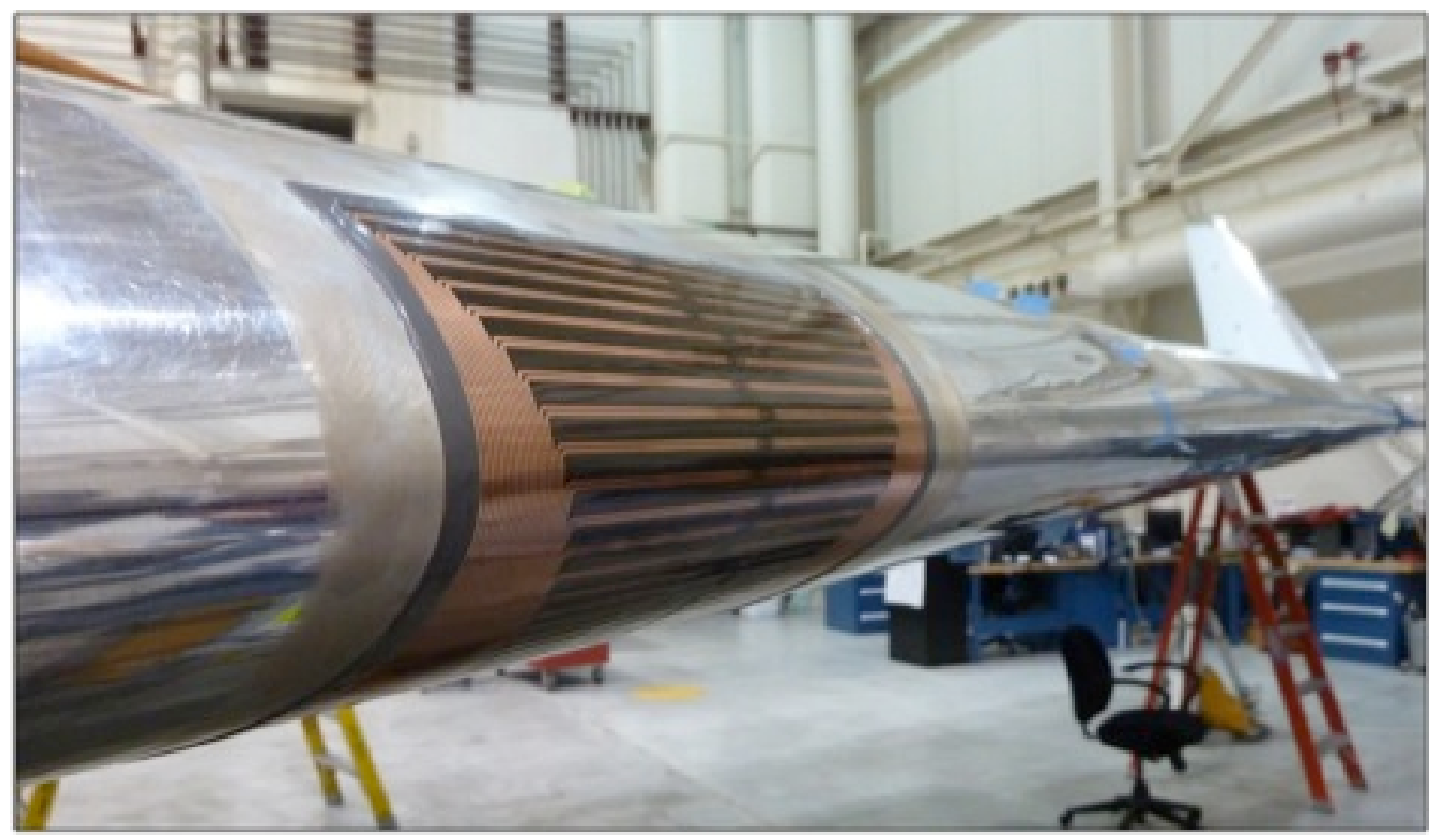

Figure 7. Hotfilm array placed on left wing leading edge.

\section{Fiber Optic Sensing System}

A fiber optic sensing system (FOSS) ${ }^{4}$ has been integrated on SCRAT. The FOSS uses light-weight fiber Bragg grating sensors to gather data that is processed to provide strain data which enables precise calculations of shape, stress, stiffness (bending and torsion), temperature, pressure, strength, and operational loads in real time. Unlike conventional strain gauges, which are heavy, bulky, and spaced at distant intervals, the fiber optic sensors are relatively small, non-intrusive, and easy to install along with providing high-resolution ( 0.5-in) strain measurements. The system allows for numerous high-fidelity measurements of structural strain and displacement captured at rates fast enough to potentially examine dynamic structural response. The FOSS gives future researchers the capability to collect, record, and telemeter over 6,000 strain measurements.

\section{Engine Parameters}

The SCRAT is instrumented to provide engine data obtained from the two Rolls-Royce Spey Mark 511-8 turbofan engines. The engine data is obtained directly from the production system and includes: fuel flow, engine pressure ratio, turbine gas temperature, high pressure tachometer, low pressure tachometer, engine oil temperature, and engine oil pressure. This data is currently being used to improve the SCRAT simulation drag and thrust models. In the future, this data can be used to provide a flight derived drag estimate for flight research experiments.

\section{Wing Strain Measurements}

Thirty-two strain gages have been attached to the left side wing surface at various locations, top and bottom to measure wing shear, bending, and torsion. The strain gages have been calibrated through the application of known loads to the airframe. Figure 8 shows the aircraft during a recent wing load calibration test. These strain gages allow for real-time monitoring of wing structural loads during flight-testing. For large-scale experiments, which require significant structural and/or aerodynamic changes to the aircraft, monitoring of the wing structural loads is an important risk mitigation step to ensure the structural loads are within the aircraft's strength capability. This capability allows for safe, rapid test point clearance during envelope expansion flights. Figure 9 shows the location for each of the strain gages. 


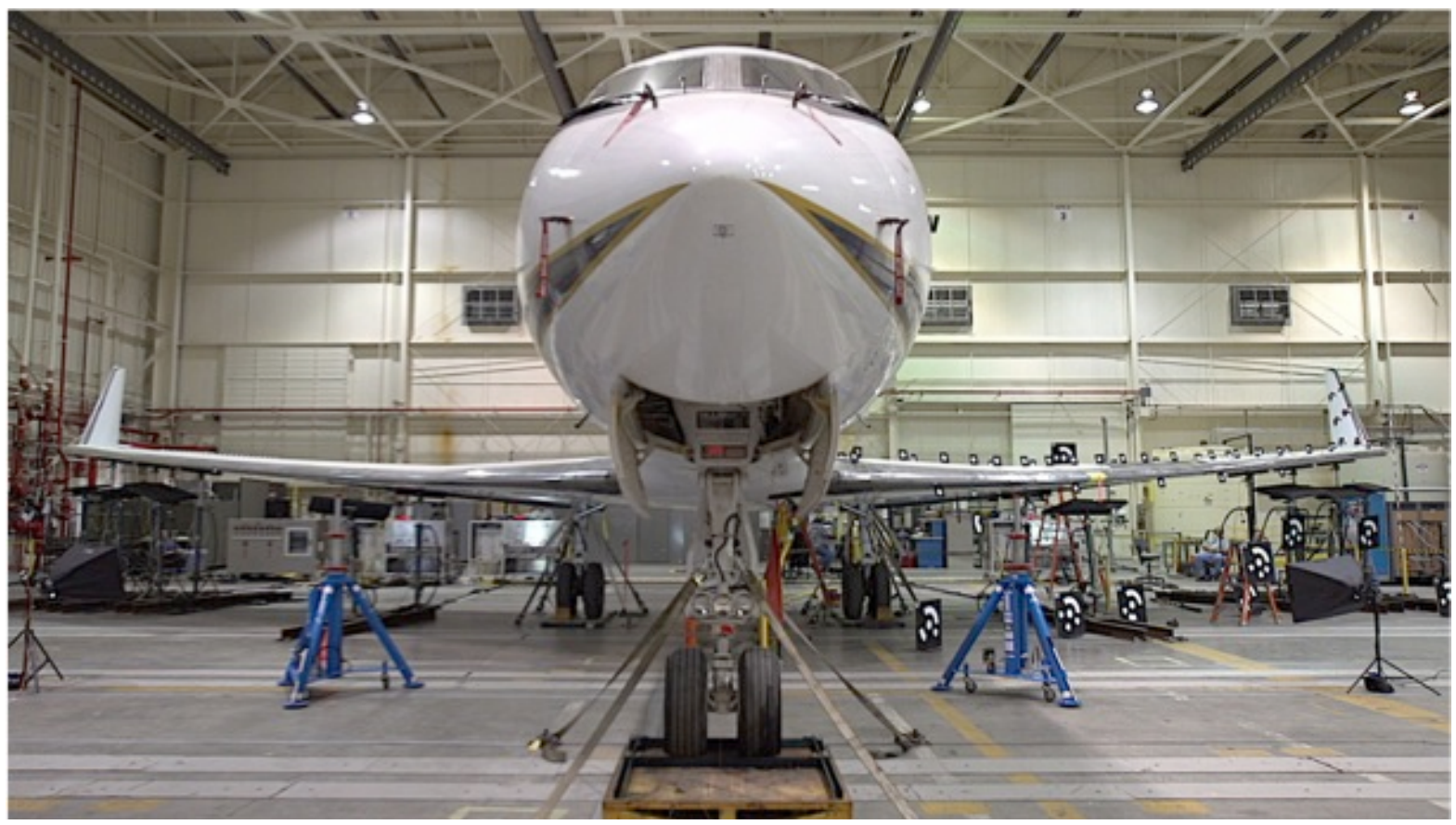

Figure 8. Calibration of the wing strain gages.

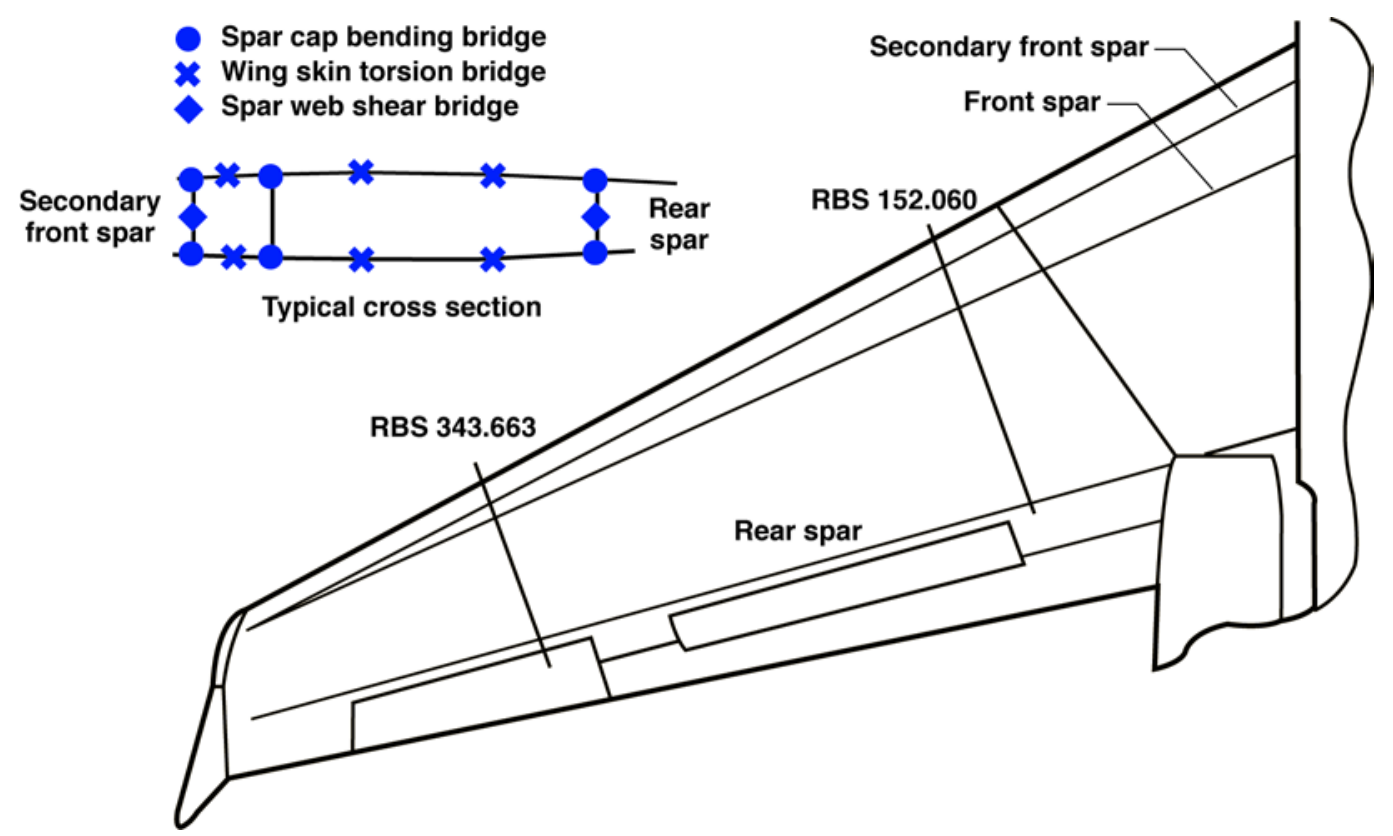

Figure 9. Location of shear, bending, and torsion strain gages on the left wing.

\section{Telemetry System Description}

The telemetry (TM) system is capable of sending two instrumentation pulse code modulation (PCM) data streams and one video stream to the control room as required. PCM data stream 1 contains the SCRAT data described in this paper. PCM data stream 2 is used for flight research experiments. These two separate PCM streams ease the integration of flight research experiments onto SCRAT since it is easier to generate a new PCM map specific to the experiment's telemetry needs rather than to make modifications to the existing SCRAT data PCM 
map. A C-Band transponder allows the DFRC Western Aeronautical Test Range (WATR) to track the aircraft during flight, which optimizes the radio frequency (RF) signal strength of all transmissions to the ground.

The C-Band Transponder, Data TM, and Video TM capabilities are listed below:

- C-Band Transponder - Receive: 5660.0 MHz, Transmit: 5585.0 MHz, Decode: 7 pseconds, Delay: 2.5 useconds.

- Data TM - Two SOQPSK transmitters are available for use. Lower-L, Upper-L, and S band are supported at data bit rates from 1-20 Mbps.

- Video TM - Tunable C-Band transmitter, Frequency Range 4400.0 to $4999.0 \mathrm{MHz}$, programmable in $1 \mathrm{MHz}$ steps.

The instrumentation system is currently configured to telemeter 5.0 Mbps of data per stream for a total capability of 10.0 Mbps. The amount of data telemetered can be tailored for the specific needs of a flight research project.

\section{E. Power Distribution System Description}

The aircraft's production electrical power distribution system (PDS) was not sufficient for the instrumentation power requirement. As a result, the production PDS was not used for the instrumentation system. An instrumentation PDS was designed and installed to provide power for the aircraft's instrumentation and research systems. The instrumentation PDS is expected to accommodate the power requirements of future flight experiments.

On the ground, the instrumentation power system can receive power from the aircraft power system while powered by a ground power cart or hangar power, the aircraft APU, and/or the engines. During flight, the power system will receive power from the engines' two alternators, which provide AC power, and two generators, which provide DC power.

With the instrumentation system as currently configured, $120 \mathrm{~A}$ of $28 \mathrm{~V} \mathrm{DC}$ and $90 \mathrm{~A}$ of $115 \mathrm{~V} 60 \mathrm{~Hz} \mathrm{AC}$ power is available for future flight research experiments. The instrumentation PDS also provides $115 \mathrm{~V} 400 \mathrm{~Hz}$ AC power to support sensor operation.

\section{F. Video System Description}

The onboard video system has the capability to record up to eleven analog cameras, and telemeter one standard definition video channel for display in the control room. The telemetered video channel can either show the output of one camera or up to four in a quad arrangement. All cameras are accessible through web browsers on the aircraft network and can be accessed by any workstation on board in order to support flight research objectives.

\section{G. Cockpit Modifications}

A number of features have been added to the SCRAT cockpit to increase test point efficiency and to aid the pilots. A g-meter has been installed in the cockpit to allow the pilots to more accurately fly to a specified g-loading. Tablet PCs have been mounted to the pilot and co-pilot yokes. These tablets are integrated with the instrumentation system and can display data to the pilots during flight to aid in conducting a flight research experiment. For example, a desired airspeed or aircraft attitude could be provided to the pilot via the tablet PC in order to obtain a specified experiment test point. A master kill switch has been added to the center pedestal to enable the pilots to shut off power to all research systems in the case of an emergency. Figure 10 shows the location of the significant cockpit modifications. 


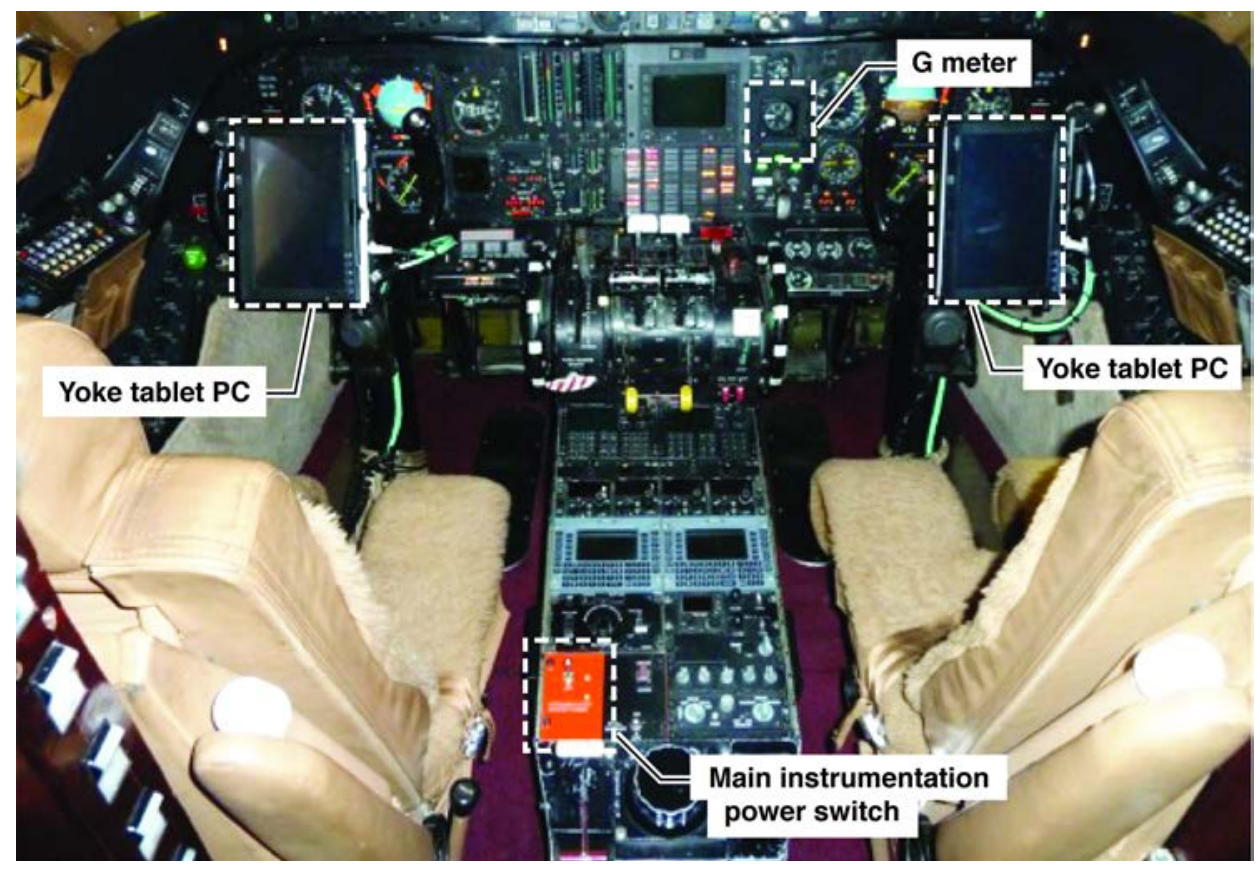

Figure 10. SCRAT cockpit.

\section{H. Cabin Description}

The SCRAT cabin has been modified to accommodate the research systems and work stations. The SCRAT cabin can be reconfigured to support a wide array of flight research experiments. Located within the cabin are a number of racks, which contain the instrumentation, power, and research systems. The current cabin layout is shown below in Fig. 11.

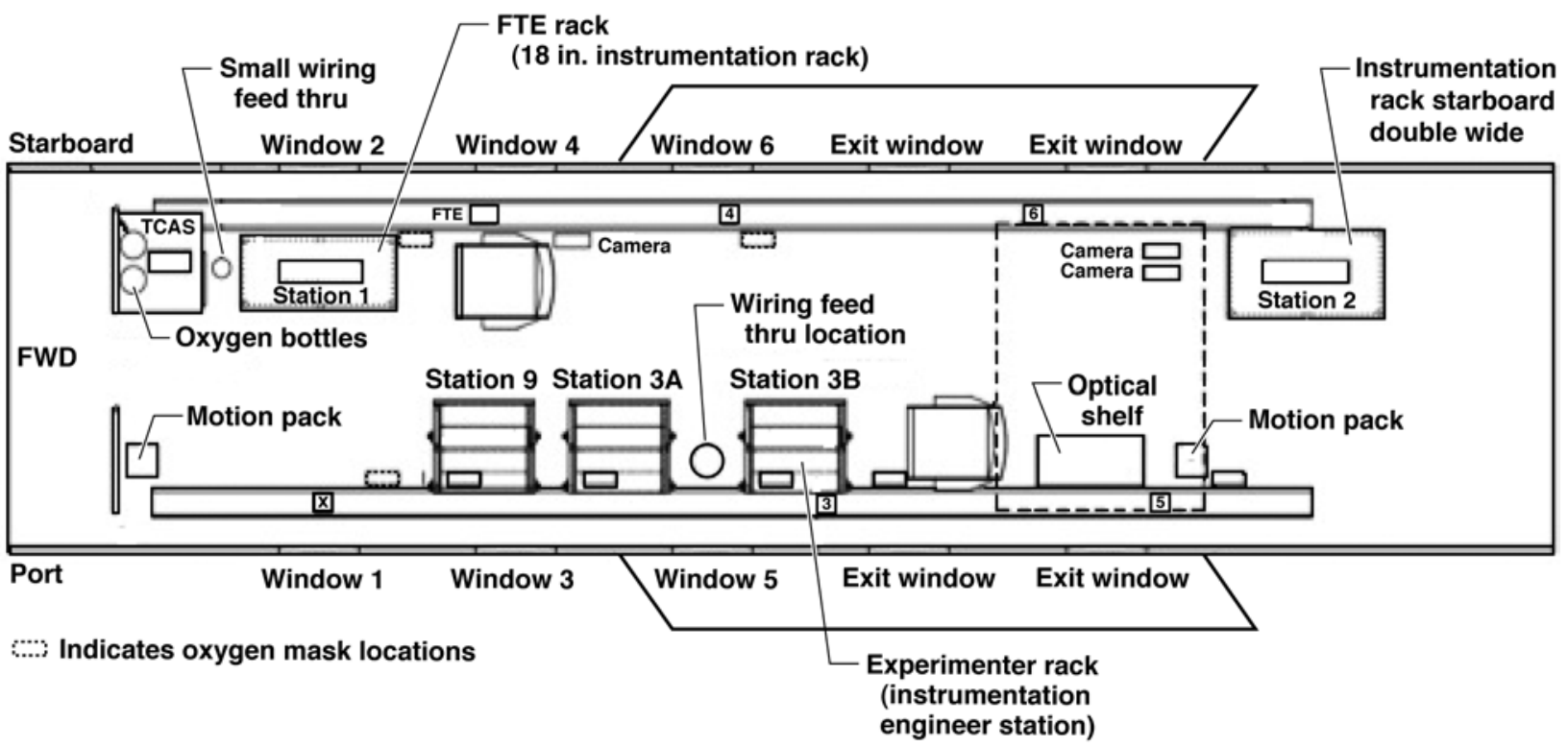

Figure 11. Current cabin layout. 


\section{Cabin Workstations}

The cabin contains two permanent workstations. Each workstation has a display, keyboard input, and seat for a researcher or crew member. Personnel at each workstation can access all of the data through the SCRAT instrumentation system through a series of configurable displays. The first permanent workstation is located on the forward right side of the aircraft and is reserved for the Flight Test Engineer (FTE). The FTE assists the aircrew in the conduct of each research mission and monitors the experiment progress from the cabin. The FTE workstation display is shown in Fig. 12. The second permanent workstation in the cabin is referred to as the instrumentation station. The instrumentation station has been used to date by an instrumentation engineer who has monitored the instrumentation system health during flight. In the future, a researcher could use the instrumentation station. In addition to the two permanent workstations, space and provisions exist to place up to three additional workstations in the cabin to support future research needs.

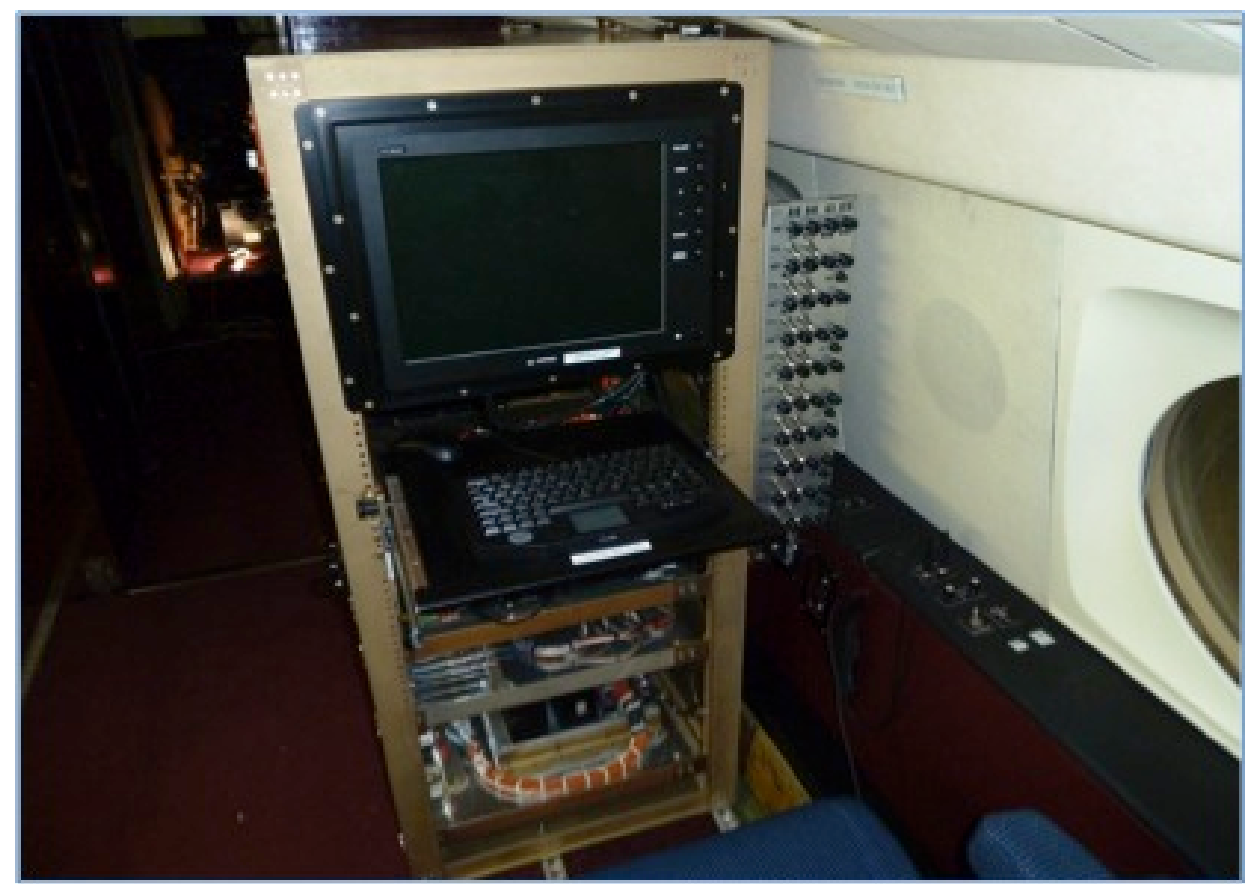

Figure 12. Station 1 FTE display.

\section{Cabin Environment}

Any electronic, electrical, and electromechanical equipment flown on SCRAT must conform to a certain level of environmental (temperature, pressure, and vibration) specifications. These specifications are generally met by testing the equipment on a mechanical shaker, which vibrates at specified frequencies and magnitudes, and through the use of an altitude chamber, which places the equipment at specified atmospheric pressures and temperatures. These environmental tests are used to detect any workmanship issues with the equipment early on and to ensure the equipment will operate in the expected flight environment. The end result of these environmental tests is an increase in the probability of a successful research flight. Table 3 details the environmental specifications for non-safety related equipment placed in the cabin.

Table 3. Non-safety critical cabin equipment environmental specifications.

\begin{tabular}{ll}
\hline \hline \multicolumn{2}{c}{ Non-safety critical cabin equipment operation environment } \\
\hline Temperature & $41^{\circ} \mathrm{F}$ to $110^{\circ} \mathrm{F}$ \\
Vibration & Curve B1 from DO-160 category R \\
Pressure & 0 to $10,000 \mathrm{ft}$ \\
\hline
\end{tabular}




\section{Communication System}

The communications system that has been integrated to the aircraft is a commercial off -the-shelf (COTS) based system, which allows additional aircrew and researchers sitting in the cabin to communicate with each other and to the pilots. In addition, the communications system allows the FTE to use the co-pilot's radio to communicate directly with the control room. The communications system allows for close coordination between researchers and the pilots to ensure the required test points are achieved.

\section{Data and Power connections}

Both AC and DC power connections are available at several locations in the cabin via wall outlets. Ethernet and serial connections are also available at these locations. The presence of these pre-existing power and data connections allows for flexibility in accommodating future flight research experiments. Figure 13 shows a representative set of power and data connections located in the cabin wall.

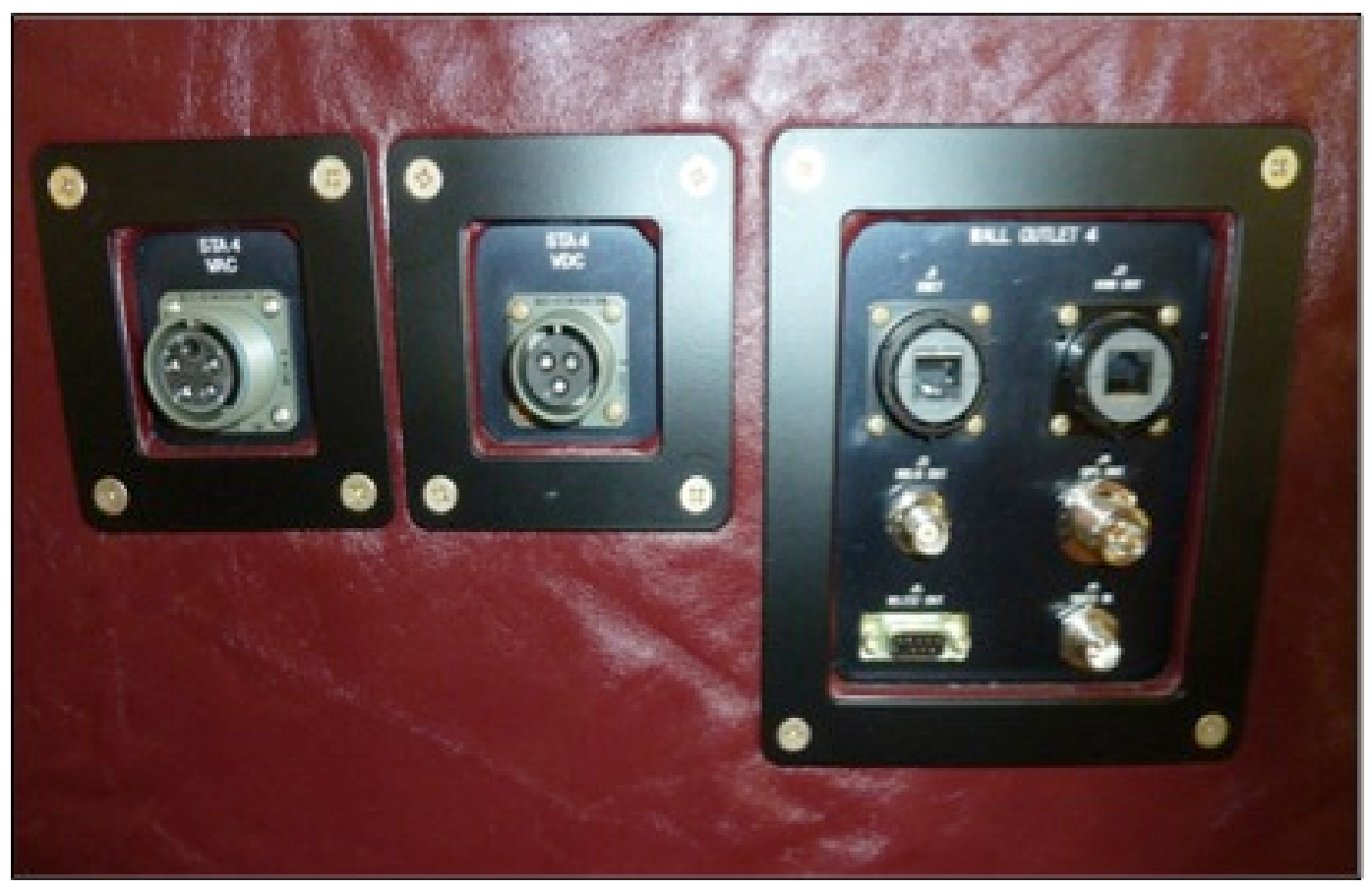

Figure 13. Representative data and power connections.

\section{External Sensor Disconnect Panel}

All of the sensors placed on the aircraft have wiring that runs from their location to the instrumentation system located in the cabin. The majority of the wiring associated with sensors placed outside of the cabin is routed to a location in the fuselage near the mid-point of the cabin where a pressure boundary pass-through exists. The sensor wiring comes into the cabin via this pass-through to a disconnect panel (Fig. 14) located on the left side of the cabin above the floor. The disconnect panel allows physical access to this sensor wiring and is where the sensor signals are passed to the instrumentation system. The sensor disconnect panel and pressure boundary pass-through contain spare connectors to accommodate future research experiments. 


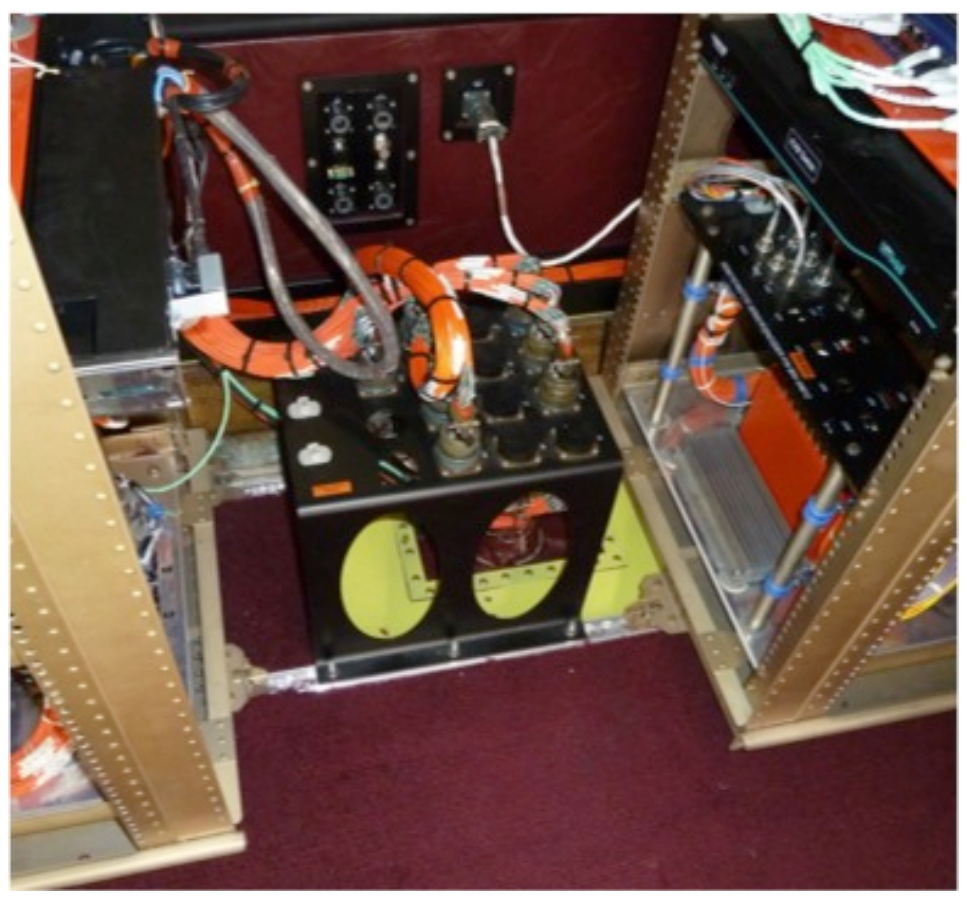

Figure 14. Sensor disconnect panel.

\section{Modified Exit Window}

One of the SCRAT's original emergency exit windows has been replaced with a custom emergency window containing two smaller panes of glass. One port is made of optical glass, and the other is made of a Zinc-Selenide pane for infrared (IR) camera use. The exit window retains the function of the original emergency exit window (Fig. 15). In addition a shelf, data connections, and power connections have been installed at this window location to allow for rapid integration of optical and IR cameras for viewing research experiments on the left wing. Figure 16 shows the modified exit window, shelf, and a sample camera installation.

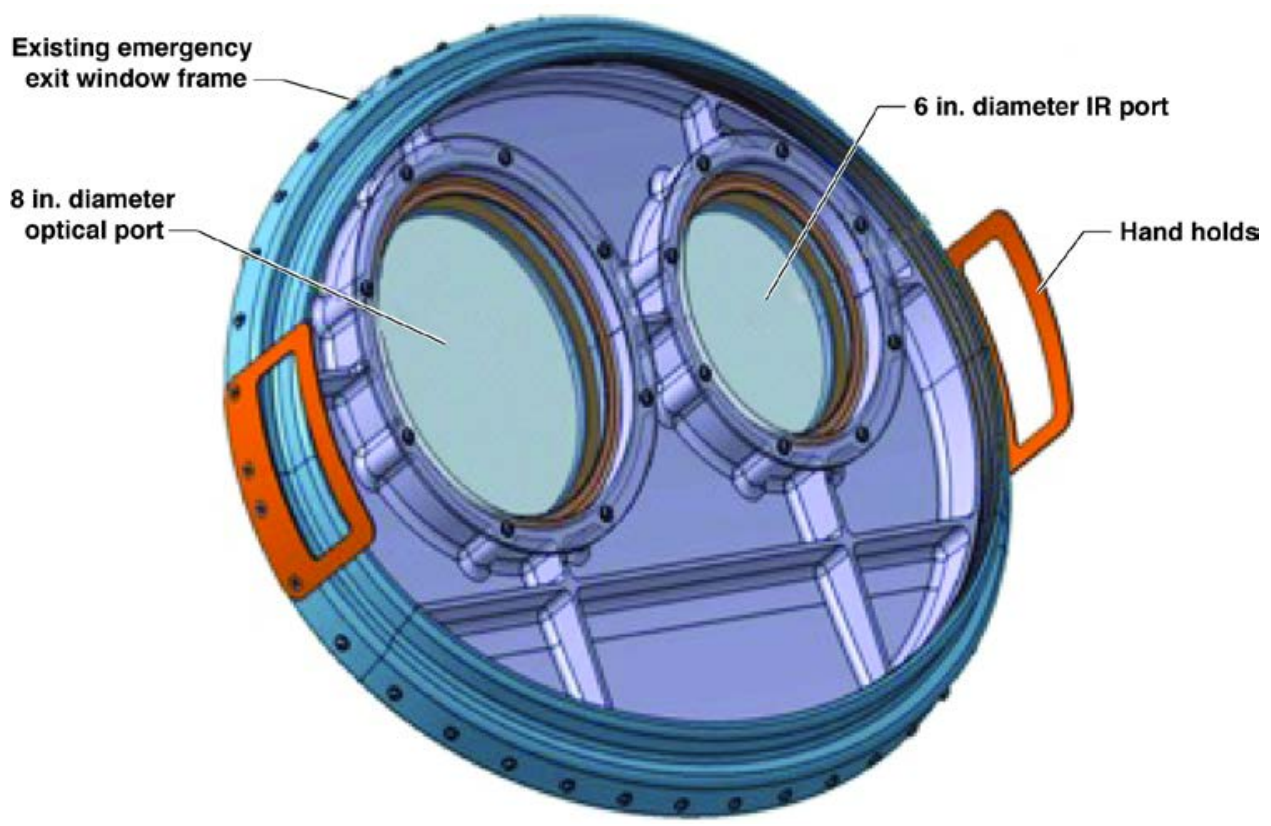

Figure 15. Modified emergency exit window.

American Institute of Aeronautics and Astronautics 


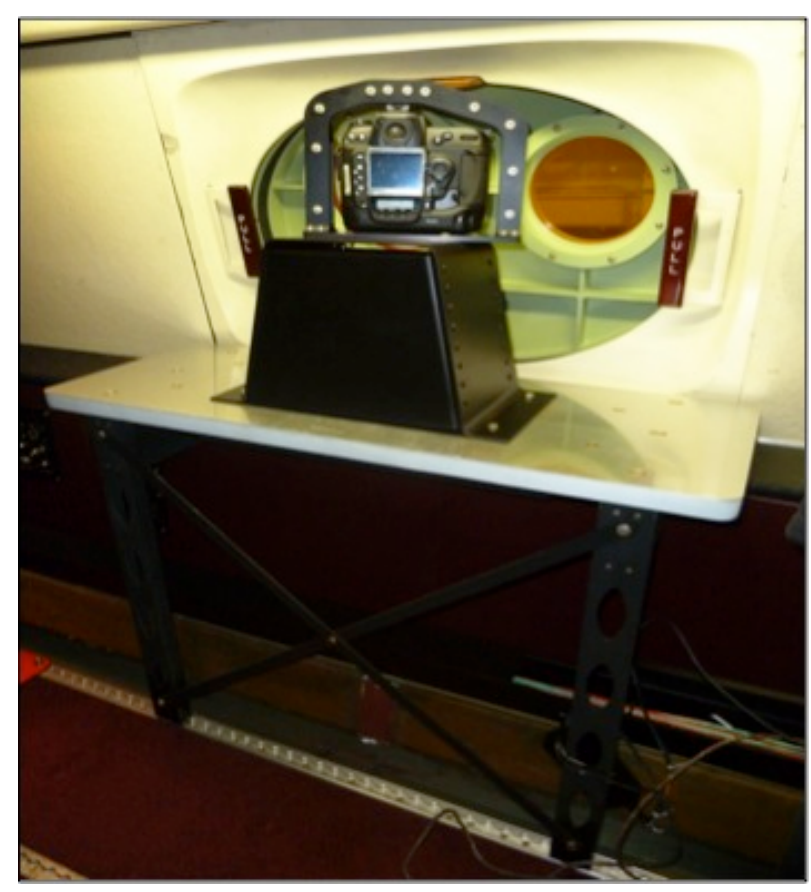

Figure 16. Optical shelf.

\section{Research Simulation}

An engineering simulation was developed which models the SCRAT flight dynamics. The simulation utilizes the DFRC Core architecture ${ }^{5}$ and contains aircraft models tailored to simulate the SCRAT systems and performance. The simulation can be run in either a real-time or batch mode of operation. The batch mode of operation allows the simulation to run as fast as the host computer can accommodate, which is significantly faster than real time allowing for numerous simulations to be rapidly run. The real-time mode of operation uses an external time source to execute the simulation in real time. The aircraft models have been updated based on flight data obtained during the baseline flights, therefore the simulation provides an accurate representation of SCRAT's in-flight handling qualities, flight dynamics, and flight performance. Figure 17 shows a sample comparison between the simulation and flight data. The flight data is taken from the baseline flights during a large-amplitude rolling maneuver. 

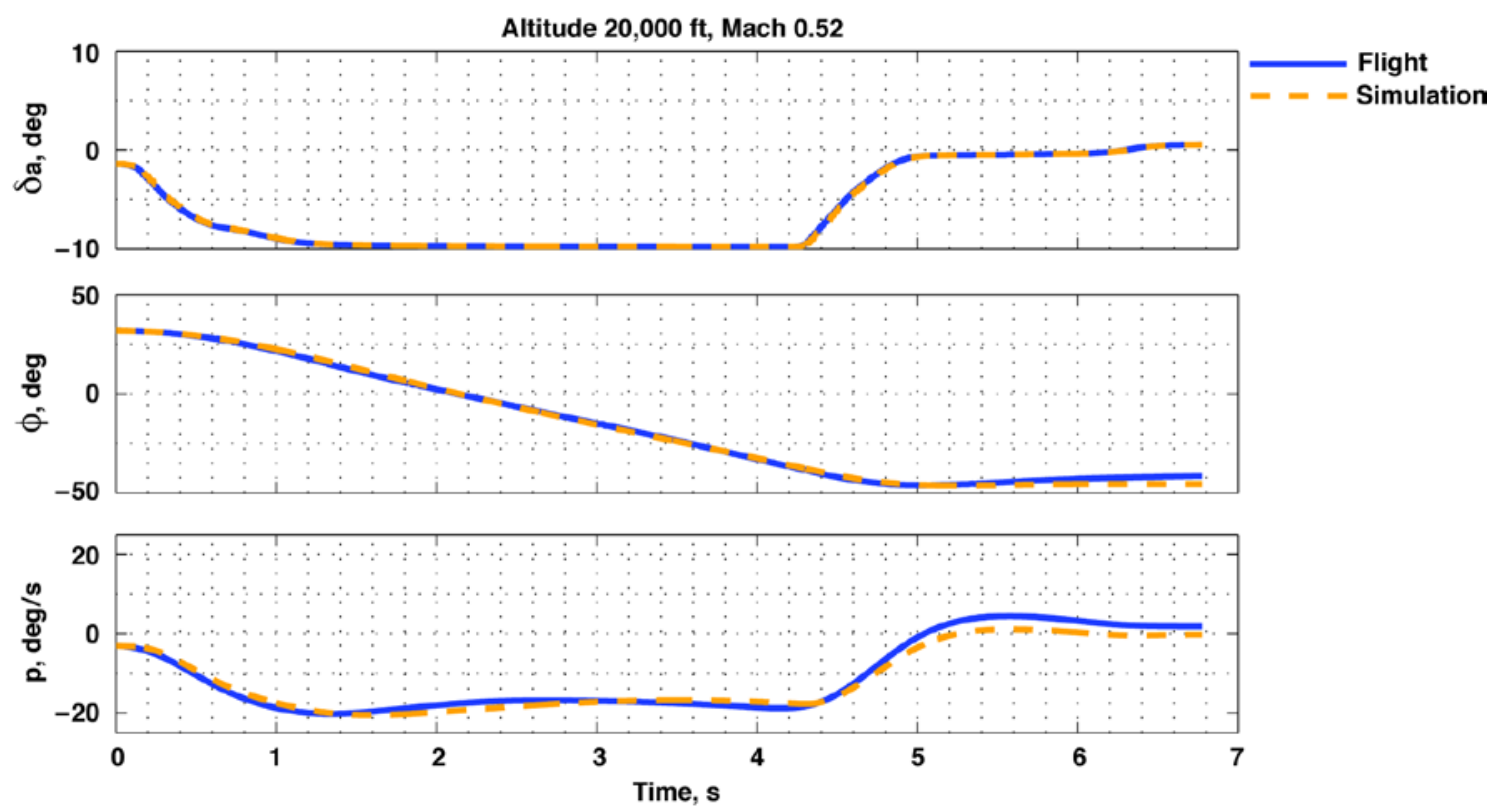

Figure 17. Sample comparison between simulation and flight data.

The effects of small- and large-scale flight experiments on the aircraft's flight dynamics can be assessed with the engineering simulation. Engineers can conduct this assessment at their desk with the batch version of the simulation. This assessment includes airworthiness analysis such as an examination of available control power, performance, handling qualities, and flight characteristics. In addition, a fixed-base cockpit simulator (Fig. 18) has been integrated with the engineering simulation to provide a basic piloted simulation capability. This piloted simulation allows for the research pilots to practice for missions and evaluate the SCRAT's predicted flight dynamics prior to envelope expansion or research flights. This ability to predict and simulate SCRAT's flight dynamics serves to prepare the pilots and greatly increases safety and mission success.

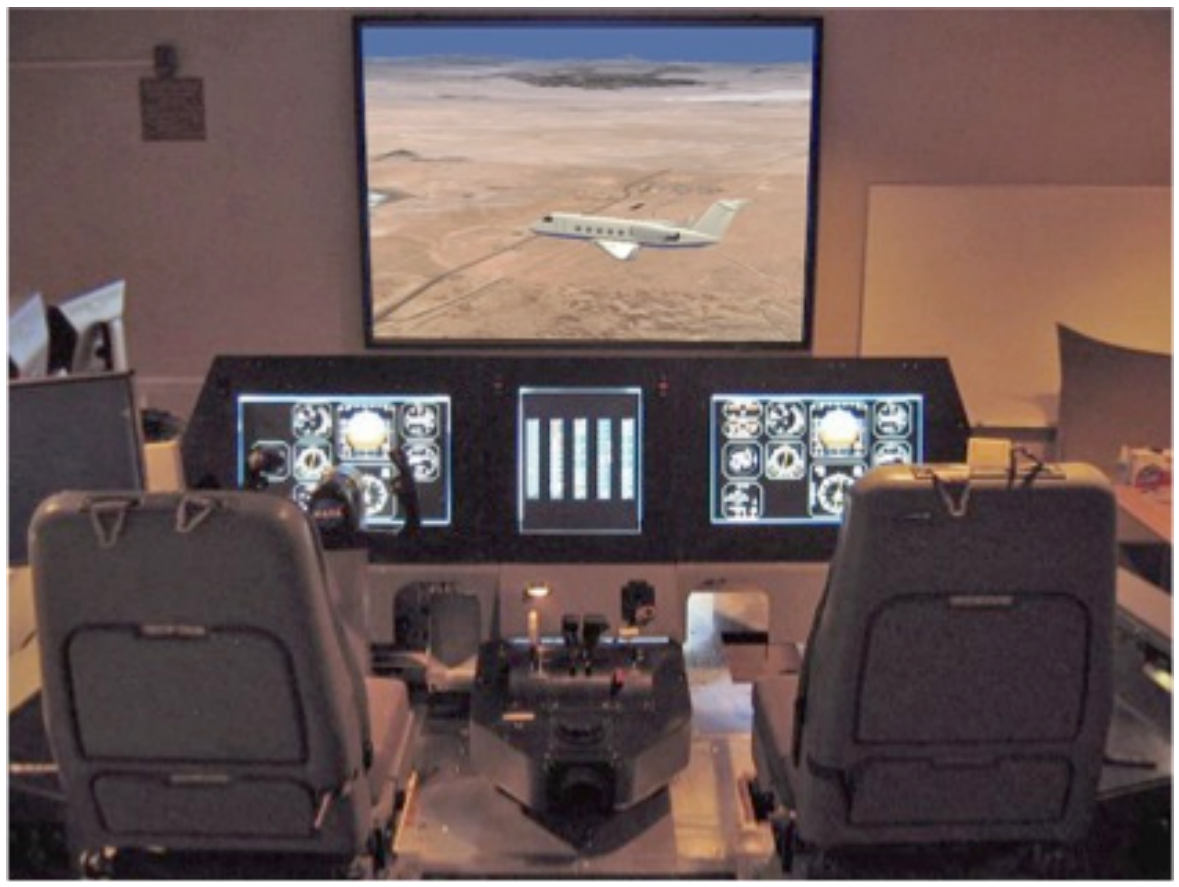

Figure 18. SCRAT fixed-base simulation.

21

American Institute of Aeronautics and Astronautics 


\section{Control Room Operations}

The NASA DFRC WATR range engineering branch provides flight-test range development services and maintains two Mission Control Centers. The major services that the range engineering branch performs are range systems engineering, test information engineering, and data processing and display system/software development. ${ }^{6}$ The SCRAT project makes use of the range engineering branch services and can utilize either control room to monitor the progress of research flights. Data available to the onboard instrumentation system can be telemetered to the control room as well as recorded on board. The telemetered data can be monitored in the control room in real time to assess the progress of flight research experiments and to ensure the flights are progressing safely. The control room displays for each discipline are created using the Interactive Display System (IADS). An example of an IADS display is shown in Fig. 19. The IADS display shown is used to monitor flight progress and aircraft status. A series of baseline displays for each discipline were developed for the baseline flights. Modifications to these displays to support future flight research experiments are relatively simple. In addition, the capability exists to execute algorithms provided by the project engineers or researchers in real time for display in the control room.

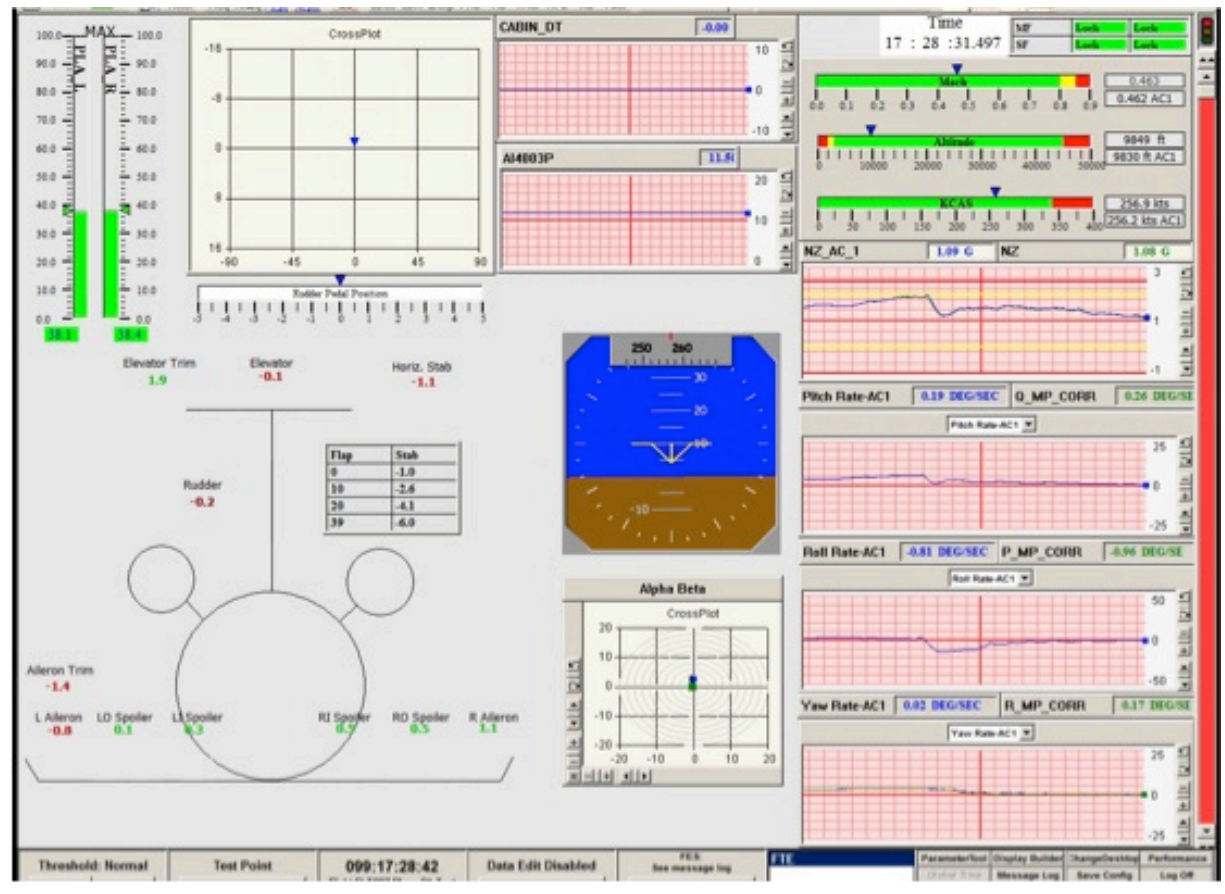

Figure 19. Sample IADS display.

Control room operations were demonstrated during the baseline flights. Figure 20 is a view of the control room during a baseline flight. During these flights, the control room was used to improve test point efficiency, ensure flight safety, and to familiarize the SCRAT team with control room operations with this platform. Following each maneuver, engineers in the control room evaluated the maneuver and assessed whether a repeat was required. When a repeat was required, feedback was provided to the pilot concerning their technique and suggestions made to improve the maneuver. Future research experiments will utilize a similar process to ensure the required data is collected. 


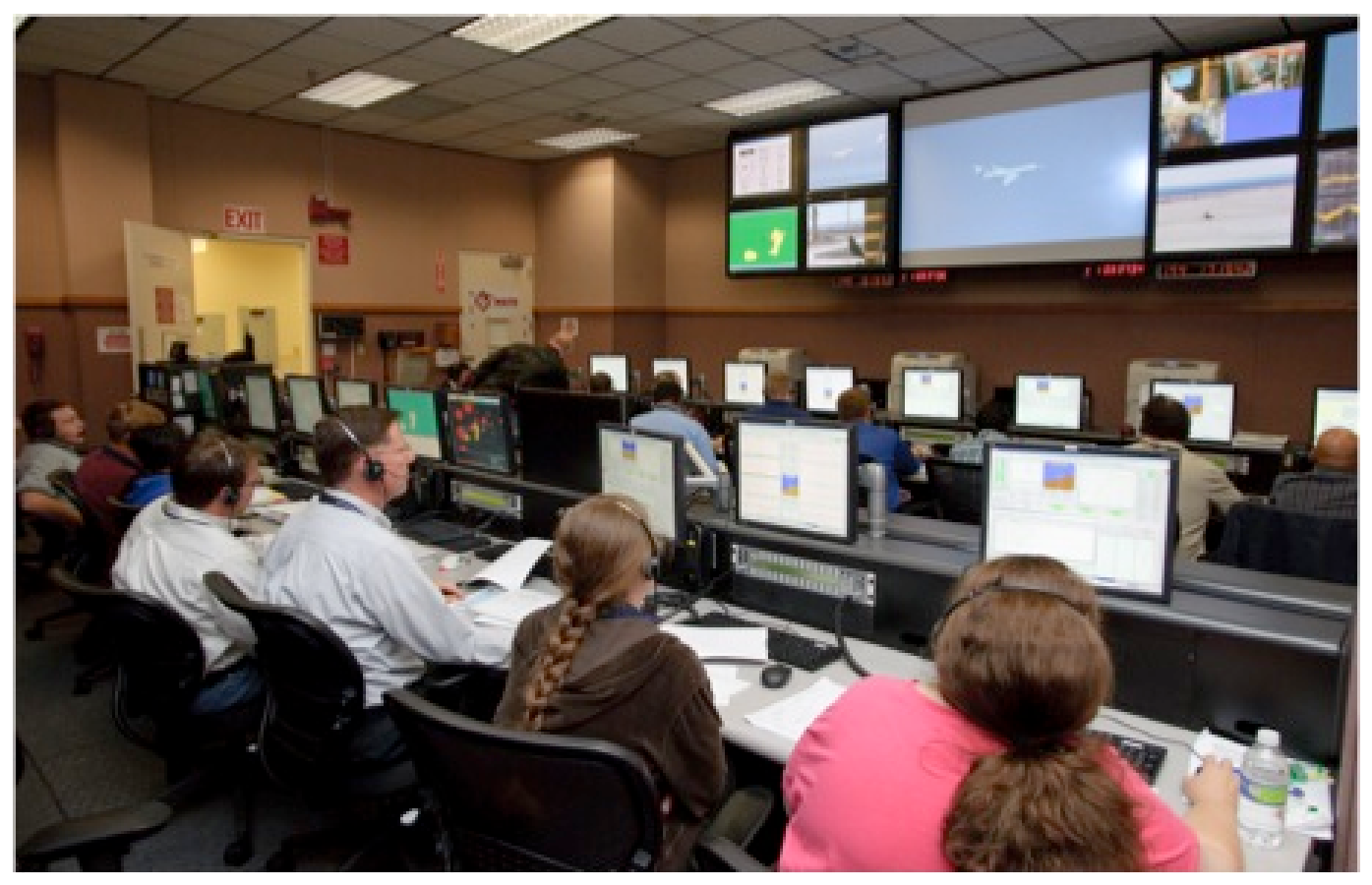

Figure 20. Control room operations during Phase 0A flights.

One video stream was sent from the SCRAT during the baseline flights. This video stream was displayed in the control room and recorded.

Currently, data is available post-flight in the following formats: CMP4, ${ }^{7}$ IADS archive, ${ }^{8}$ and Chapter $10 .{ }^{9}$ In order to accommodate research needs, data can be made available in nearly any format desired. Flight data is typically available within 24 hours of the completion of a flight.

\section{Baseline Flight Data}

The baseline flights consisted of a series of flights, which gathered approximately 30 hours of data on the SCRAT's flight characteristics to improve engineering and simulation models, and gather data to support the planned flight research experiments. Figure 21 shows the flight conditions that were flown during the baseline flights. During these characterization flights, data was gathered to calibrate several of the new research systems on the aircraft, including the airdata system. In addition, the baseline flights verified and validated the SCRAT instrumentation system operation and instrumentation PDS modifications. 


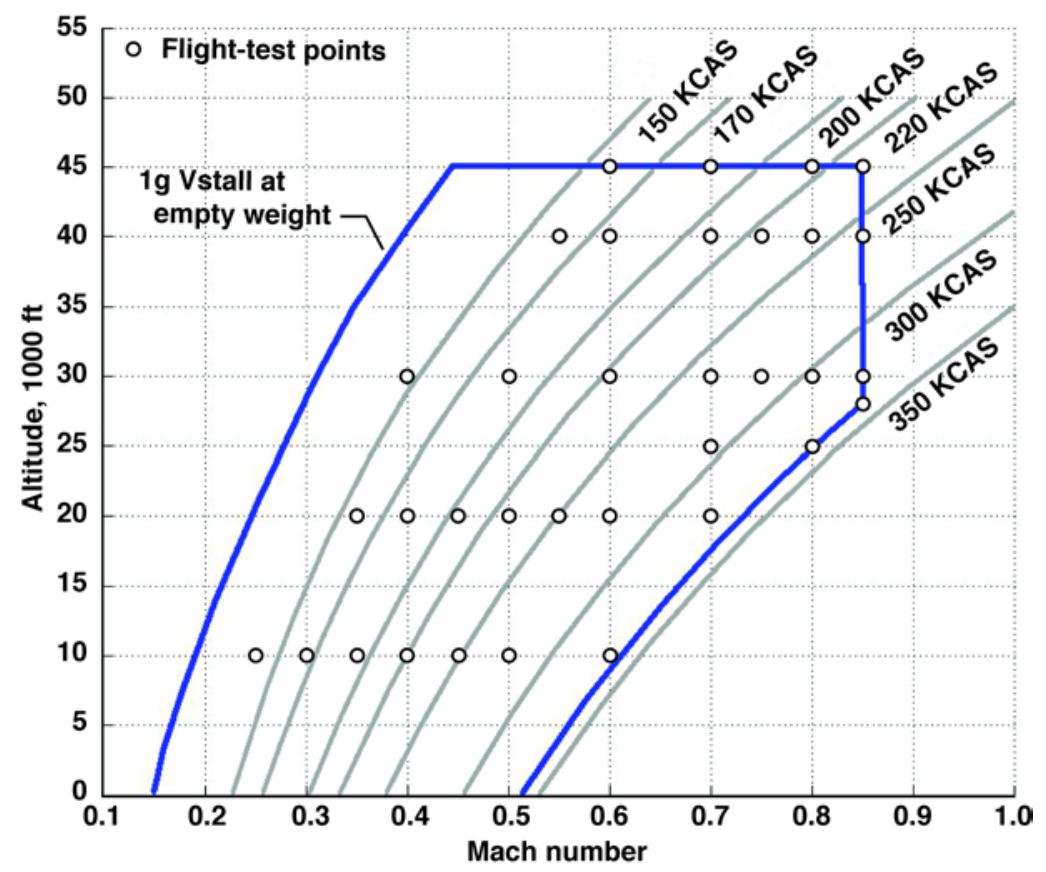

Figure 21. Baseline characterization flight data points.

During the baseline flights, the SCRAT was flown at select points throughout the flight envelope with the purpose of obtaining PID and handling quality data. This data was used to update the aerodynamics database and validate the updates. Control surface positions and pilot inputs recorded in flight were used to more closely match the handling qualities of the piloted simulation to the aircraft. Wing pressure measurements recorded in flight characterized the flow-field over the left wing for future research projects. A limited set of engine performance data has been gathered to support future research experiments.

\section{Flight Research Experiment Examples}

Two flight research experiments have been developed to various extents for flight on SCRAT. The Discrete Roughness Element (DRE) Laminar Flow Glove Experiment (DRELFGE) was funded by NASA's Environmentally Responsible Aviation (ERA) Project to modify a portion of the left wing to conduct flight research into using DREs as a laminar flow control method. The Adaptive Compliant Trailing Edge (ACTE) is funded by both ERA and the Air Force Research Laboratory (AFRL) (Wright-Patterson Air Force Base, Ohio) to flight-test large-scale compliant structures. The DRELFGE and ACTE projects are briefly discussed as examples of large-scale flight research experiments that can be flown on SCRAT.

\section{A. DRE Laminar Flow Glove Experiment}

The DRELFGE was developed to demonstrate a passive laminar flow control technique at Reynolds numbers representative of a business class aircraft. The flow control technique to be explored is the DREs developed by Texas A\&M University (TAMU) (College Station, Texas). DREs are elements a few microns high and 1-2 millimeters in diameter that are placed near the leading edge to control cross-flow boundary layer instabilities. This technology has the potential to increase laminar flow over the wings thereby resulting in less drag and less fuel burn relative to current aircraft. The DRELFGE consisted of a highly instrumented wing glove (Fig. 22) with a row of DREs installed, placed on the left wing of the SCRAT. The flight research conducted with the DRELFGE installed on the SCRAT would yield quantitative and qualitative data, which can be used to design a natural laminar flow airfoil. The qualitative data consists of an infrared image of the left wing, which would visually show the areas of laminar and turbulent flow. An infrared camera located inside the cabin would look through the modified exit window to obtain the infrared image of the wing. The quantitative data consists of wing pressure distributions, temperatures, airdata, and aircraft state information. Various surface roughness configurations of the DRELFGE would also be tested to determine the utility of DREs in maintaining laminar flow on a surface painted similar to that of transport class aircraft. 


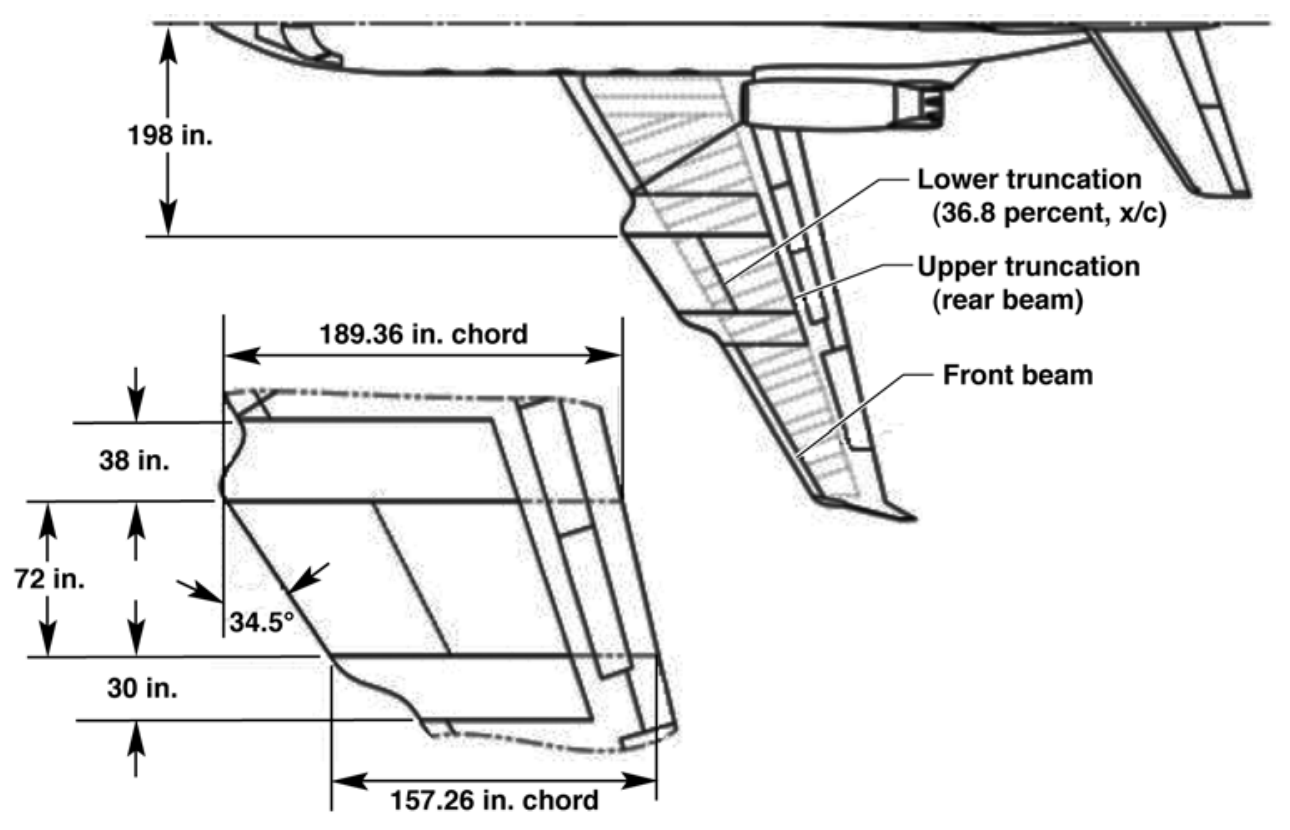

Figure 22. Notional DRELFGE test section location.

The SCRAT's wing chord, wing sweep, and flight envelope allow the exploration of technologies such as DREs at flight conditions representative of transport class aircraft. The SCRAT is an excellent platform for this type of work due to the existing instrumentation and power systems that can accommodate the additional research instrumentation. The SCRAT is also a good fit for accommodating experiments such as the DRELFGE since the wing structure can accommodate the additional structural loads associated with flying experiments such as this.

The DRELFGE wing glove design has been optimized for flight on the SCRAT, ${ }^{10}$ passed a PDR in June of 2012, and is currently on hold while options to conduct this research are being evaluated.

\section{B. Adaptive Compliant Trailing Edge}

NASA DFRC is working in conjunction with the AFRL and FlexSys, Inc. (Ann Arbor, Michigan) to design, develop, and fly the ACTE. The ACTE will design, build, and flight-test two adaptive compliant composite flaps for integration on the SCRAT. Adaptive compliant control surfaces enable the development of adaptive airfoils. Numerous studies have shown the aerodynamic benefits of an adaptive airfoil, though a full-scale flight demonstration is needed to establish confidence in an adaptive compliant structure. ${ }^{11,12}$ The ACTE project is an interim step on the path towards developing and demonstrating compliant structures for aircraft design. The focus is on developing compliant structures and demonstrating their integration and flight; compliant structure actuation and demonstrating the aerodynamic benefits are not a part of the ACTE project. Figure 23 is an illustration of what the ACTE flaps will look like on SCRAT. The ACTE flaps will replace the SCRAT's existing fowler flaps. The ACTE flaps will not be actuated in flight. Instead, each ACTE flap will be set to a pre-determined position on the ground prior to each flight. It is desired to fly the flaps at deflections ranging from $-2^{\circ}$ to $+30^{\circ}$. 


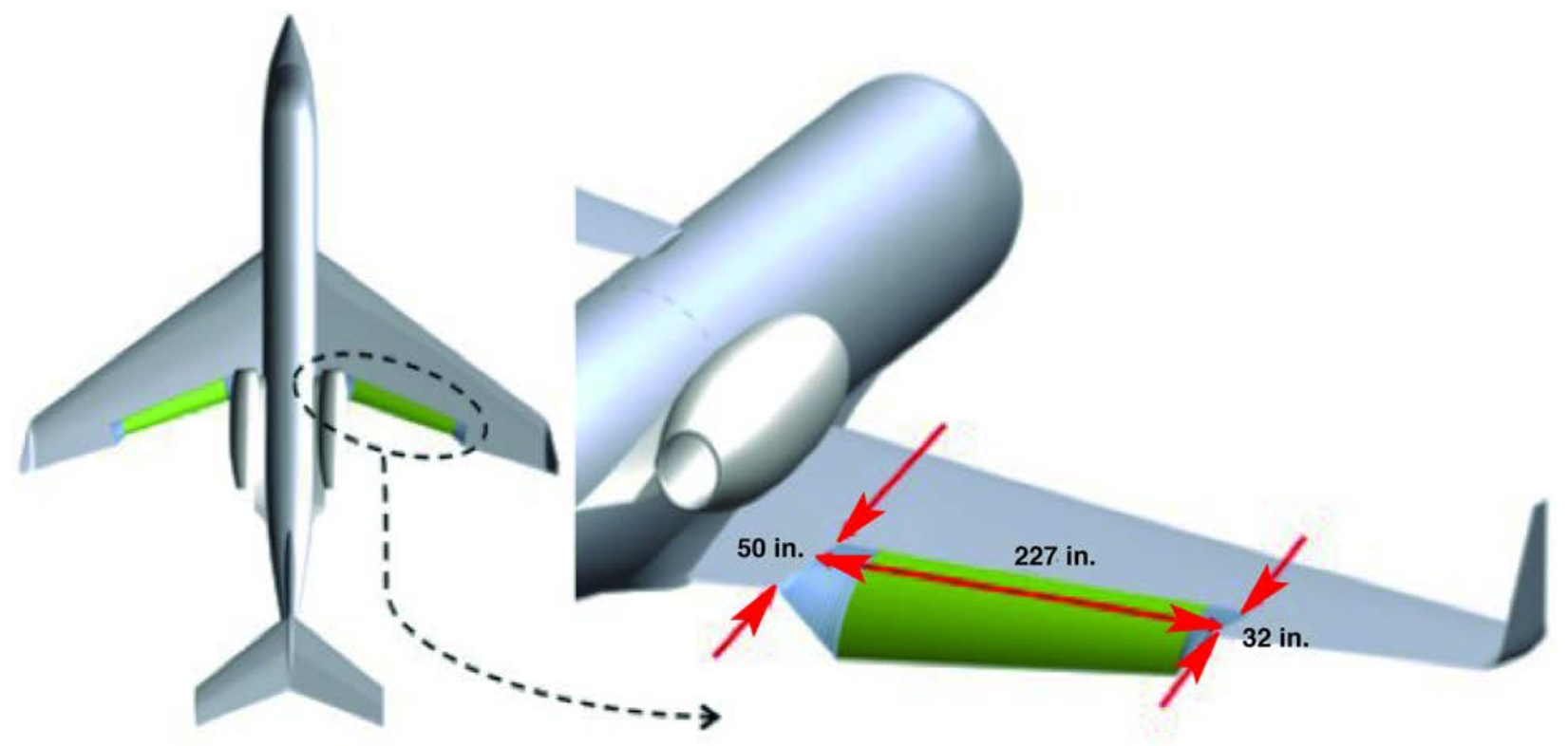

Figure 23. The ACTE installation on the SCRAT with inboard and outboard transition surfaces (blue) and a main flap (green).

The installation of the ACTE flaps requires the removal of the SCRAT spoilers along with numerous modifications to the aircraft systems. These spoilers provide approximately half of the pilot's roll control performance, and their removal was identified as a risk. In order to mitigate this risk, a series of flights known as the ACTE risk reduction (ARR) flights was conducted. The ARR flights consisted of approximately 12 hours of flight time with the SCRAT's spoilers disabled, thus replicating the roll control performance that the pilots can expect when flying the ACTE flaps. In addition, several of the aircraft system modifications related to aircraft system alarms were implemented to verify them prior to flight testing the ACTE flaps. The ARR flights were very successful and demonstrated that the pilots can safely fly SCRAT with the flight spoilers disabled/removed. Prior to the ARR flights, the SCRAT simulation had been modified to replicate the predicted handling qualities of the SCRAT with the flight spoilers disabled. The pilots used the simulation to practice landing and maneuvering in advance of the flights, and they found this experience was instrumental to the success of the ARR flights.

Similarly to the DRELFGE experiment, ACTE is an example of how SCRAT's capabilities enable the flight testing of novel experiments, such as new, large-scale control surfaces. For example, the SCRAT wing strain measurements are an important risk reduction feature for the ACTE project since they allow for real-time monitoring of the wing structural loads in flight, thereby helping to ensure safe operation. In addition, ACTE demonstrates the depth and versatility of the SCRAT team in integrating an experiment which affects the aircraft's aerodynamics, structural loads, flutter characteristics, and handling qualities.

The ACTE project completed a CDR in June of 2013. The ACTE flaps are undergoing initial build-up and plan to be integrated onto the SCRAT during 2013, with the flight-testing occurring in 2014. A control room will support the ACTE flights since this is a large-scale modification to the aircraft.

\section{Conclusion}

This paper described the SCRAT's research systems and capabilities. The SCRAT can accommodate a range of small and large-scale flight research experiments. Coupled with the development of the ground-based tools and knowledge base, the SCRAT provides a powerful capability for NASA and the nation to perform aerodynamics research, raise the Technology Readiness Level (TRL) of advanced technologies, demonstrate technologies in flight, and gather high-quality research data suitable for verifying the technologies and validating design and analysis tools. 


\section{References}

${ }^{1}$ National Research Council, Recapturing NASA's Aeronautics Flight Research Capabilities, The National Academies Press, Washington D. C., 2012.

${ }^{2}$ Rae, W. H. Jr., and Pope, A., Low-Speed Wind Tunnel Testing, John Wiley and Sons, Inc., New York, 1984.

${ }^{3}$ Tao Systems, Senflex ${ }^{\circledR}$ Multi-Element Surface Hot-Film Sensors, URL: http://www. taosystem.com/products/senflex/ [cited 5, July 2013].

${ }^{4}$ Bakalyar, J., "Fiber-Optic Strain Sensing (FOSS) Shape and Load Mesurement Demonstration Tests,” National Aeronautics and Space Administration, Dryden Flight Research Center URL: http://ntrs.nasa.gov/archive/nasa/casi.ntrs.nasa.gov/ 20110014495_2011014995.pdf [cited 5, July 2013].

${ }^{5}$ Curlett, B. P., “A Software Framework for Aircraft Simulation,” NASA/TM-2008-214639, 2008.

6 National Aeronautics and Space Administration, Mission Information and Test Systems, URL: http://www1.nasa.gov/centers/dryden/capabilities/CodeM/CodeMC/index.html [cited 5, July 2013].

7 National Aeronautics and Space Administration, Flight Data Access System Programmer's Manual-2003, URL: https://dfrcshare.ndc.nasa.gov/Orgs/codeM/codeMI/Ops/DataCenter/ SitePages/FDAS\%20Programmer\%20Manual.aspx [cited 5, July 2013].

${ }^{8}$ Symvionics, Incorporated, IADS Product Descriptions, URL: http://iads.symvionics.com/ productsdesc.html [cited 5, July 2013].

${ }^{9}$ U.S. Army/WSMR, Telemetry Standards, RCC Document 106-07, Chapter 10, September 2007 URL: http://www.wsmr. army.mil/RCCsite/Documents/106\%20Previous\%20Versions/106-07/106-07\%20Cover\%20-\%20TOC\%20-\%20Changes\%20\%20Preface.pdf [cited 5, July 2013].

${ }^{10}$ Hartshorn, F., Belisle, M. J., and Reed, H. L., “Computational Optimization of a Natural Laminar Flow Experimental Wing Glove,” AIAA-2012-870, 2012.

${ }^{11}$ Sridhar, K., Osborn, R., Ervin, G., Flick, P., and Paul, D., "Mission Adaptive Compliant Wing - Design, Fabrication and Flight Test,” Symposium on Morphing Vehicles, RTO-MP-AVT-168, Lisbon, Portugal, 2009, p. 18-1.

${ }^{12}$ Nangia, R. K., "Study for Air Vehicles at High Speeds Identifying the Potential Benefits to Transport Aircraft of a Continuously Variable Geometry Trailing-Edge Structure that can be Utilized for Aircraft Control, Trim, Load-Alleviation, and High Lift,” AFRL-AFOSR-UK-TR-2011-029, 2011. 